Article

\title{
Novel Hybrid Data-Intelligence Model for Forecasting Monthly Rainfall with Uncertainty Analysis
}

\author{
Zaher Mundher Yaseen ${ }^{1, *(\mathbb{D}}$, Isa Ebtehaj ${ }^{2}{ }^{\oplus}$, Sungwon Kim ${ }^{3}$, Hadi Sanikhani ${ }^{4}{ }^{\oplus}$, H. Asadi $^{5}$, \\ Mazen Ismaeel Ghareb ${ }^{6}$ (D) , Hossein Bonakdari ${ }^{2}$ (D), Wan Hanna Melini Wan Mohtar ${ }^{7}$, \\ Nadhir Al-Ansari ${ }^{8}$ (D) and Shamsuddin Shahid ${ }^{1, *(D)}$ \\ 1 School of Civil Engineering, Faculty of Engineering, Universiti Teknologi Malaysia, 81310 Skudai, \\ Johor Bahru, Malaysia \\ 2 Department of Civil Engineering, Razi University, 97146 Kermanshah, Iran; isa.ebtehaj@gmail.com (I.E.); \\ bonakdari@yahoo.com (H.B.) \\ 3 Department of Railroad Construction and Safety Engineering, Dongyang University, 36040 Yeongju, Korea; \\ swkim1968@dyu.ac.kr \\ 4 Water Engineering Department, Agriculture Faculty, University of Kurdistan, 66177-15175 Sanandaj, Iran; \\ h.sanikhani@uok.ac.ir \\ 5 Water Engineering Department, Faculty of Agriculture, University of Tabriz, 51666-16471 Tabriz, Iran; \\ hasadi_wre@yahoo.com \\ 6 Department of Computer Science, College of Science and Technology, University of Human Development, \\ 46001 Sulaymaniyah, Iraq; mazen.ismaeel@uhd.edu.iq \\ 7 Sustainable and Smart Township Research Centre (SUTRA), Faculty of Engineering and Built Environment, \\ Universiti Kebangsaan Malaysia, 43600 Bangi, Selangor, Malaysia; hanna@ukm.edu.my \\ 8 Civil, Environmental and Natural Resources Engineering, Lulea University of Technology, 97187 Lulea, \\ Sweden; nadhir.alansari@ltu.se \\ * Correspondence: myzaher@utm.my (Z.M.Y.); sshahid@utm.my (S.S.)
}

Received: 23 January 2019; Accepted: 6 March 2019; Published: 10 March 2019

\begin{abstract}
In this research, three different evolutionary algorithms (EAs), namely, particle swarm optimization (PSO), genetic algorithm (GA) and differential evolution (DE), are integrated with the adaptive neuro-fuzzy inference system (ANFIS) model. The developed hybrid models are proposed to forecast rainfall time series. The capability of the proposed evolutionary hybrid ANFIS was compared with the conventional ANFIS in forecasting monthly rainfall for the Pahang watershed, Malaysia. To select the optimal model, sixteen different combinations of six different lag attributes taking into account the effect of monthly, seasonal, and annual history were considered. The performances of the forecasting models were assessed using various forecasting skill indicators. Moreover, an uncertainty analysis of the developed forecasting models was performed to evaluate the ability of the hybrid ANFIS models. The bound width of $95 \%$ confidence interval (d-factor) and the percentage of observed samples which was enveloped by $95 \%$ forecasted uncertainties (95PPU) were used for this purpose. The results indicated that all the hybrid ANFIS models performed better than the conventional ANFIS and for all input combinations. The obtained results showed that the models with best input combinations had the (95PPU and d-factor) values of (91.67 and 1.41), (91.03 and 1.41), (89.74 and 1.42), and (88.46 and 1.43) for ANFIS-PSO, ANFIS-GA, ANFIS-DE, and the conventional ANFIS, respectively. Based on the 95PPU and d-factor, it is concluded that all hybrid ANFIS models have an acceptable degree of uncertainty in forecasting monthly rainfall. The results of this study proved that the hybrid ANFIS with an evolutionary algorithm is a reliable modeling technique for forecasting monthly rainfall.
\end{abstract}

Keywords: hybrid ANFIS model; rainfall time series forecasting; stochasticity; uncertainty analysis 


\section{Introduction}

It is worth mentioning that rainfall is the only input element source for the hydrologic cycle. However, excessive rainfall and the scarcity of it on Earth affect the tremendous flooding and severe drought that occur over short and long intervals [1]. Rainfall forecasting, therefore, can prevent the many natural disasters, thereby saving human lives. The accuracy of rainfall forecasting can also help the preparation of efficient structural and non-structural designs for disaster management. The accuracy of rainfall time series forecasting depends on the methods used (e.g., stochastic or deterministic) for uncertainty mitigation. Deterministic dynamical forecasting models are developed based on the physical laws related to land-ocean-atmosphere interactions and are thus able to predict changes in rainfall due to changes in Earth's atmosphere. However, the forecasted rainfall provided by dynamical models is often prone to large error at the local scale [2]. Statistical models are simple to implement and operate and have been found to forecast more efficiently the smooth changes in rainfall at the local scale. Therefore, statistical models are often preferred for rainfall forecasting at the local scale [3-6]. Time series modeling has been a very interesting topic not only for hydrological problems, but also for numerous science and engineering applications [7,8]. For this research, the motivation was to explore reliable and robust hybrid intelligence models that were capable of mimicking the existing non-linear pattern in rainfall by analyzing the historical information and understanding the internal mechanism of the time series data.

Research studies on hybrid techniques using data-driven models, such as artificial neural networks (ANNs), genetic programming (GP), and adaptive neuro-fuzzy inference systems (ANFISs), integrated with different optimization methods (e.g., particle swarm optimization (PSO), genetic algorithm (GA), and differential evolution (DE) algorithm) [9] have been published over the past decades and demonstrated positive outcomes for solving hydrology and water resource problems, such as rainfall runoff, river stage, evaporation, sediment, and groundwater, etc. [10-15]. Abrahart et al. [16] used a pruning algorithm (PA) and a genetic algorithm (GA) to optimize data-driven models for runoff forecasting. They compared model performances using different forecasting methods. Chau [17] applied a particle swarm optimization (PSO) algorithm to train ANNs for river stage prediction. He found that PSO could optimize the applied ANNs. In other research, Chau [18] developed a split-step particle swarm optimization (SSPSO) algorithm to train a multilayer perceptron (MLP) for forecasting river stage using different lag times. The author concluded that MLP-SSPSO forecasted the river stage more accurately compared to MLP-PSO. Chen and Chang [19] applied GA and a scaled conjugate gradient algorithm (SCGA) to train feedforward neural networks (FFNN) for forecasting reservoir inflow. They demonstrated that the accuracy of FFNN-GA and FFNN-SCGA was superior to stochastic models. A combined artificial bee colony (ABC) algorithm with ANNs was conducted by [20] to demonstrate the discharge-suspended sediment relationship. They concluded that ANNs-ABC can derive the relationship between discharge and suspended sediment more effectively compared with ANFIS, ANNs, and the rating-curve model. Asadnia et al. [21] developed the improved particle swarm optimization (IPSO) algorithm to train ANNs for predicting river stage. They concluded that the results of ANNs-IPSO were better compared to those of ANNs-PSO, ANNs-conjugate gradient (ANNs-CG), ANNs-gradient descent (ANNs-GD), and ANNs-Levenberg Marquardt (ANNs-LM), respectively. Sudheer et al. [22] applied PSO to train support vector machines (SVMs) for forecasting river discharge. They compared SVMs-PSO with autoregressive moving average model (ARMA) and ANNs and concluded that SVMs-PSO was better than ARMA and ANNs. Taormina and Chau [23] introduced the multi-objective fully informed PSO (MOFIPSO) to train ANNs for predicting river discharge. They showed that the results of ANNs-MOFIPSO were better than ANNs-SPSO. Kalteh [24] combined wavelet GA (WGA) with the support vector regression (SVR) for forecasting long-term discharge. The author reported that SVR-WGA provided better forecasting compared to SVR-GA. Annaty et al. [25] used PSO to train ANFIS for predicting scour depths. They found that ANFIS-PSO was better than ANNs-PSO, FDOT, and HEC-18, respectively. 
Although there have been previous research studies on the joint use of data-driven models and optimization methods, specific investigations on rainfall forecasting using hybrid methods have been limited so far. The hybridization of evolutionary algorithms with a data-driven model showed a remarkable enhancement in the modeling of hydrological processes [26-29]. Hence, to the best of the authors' knowledge, and for the first time, a hybrid ANFIS model integrated with three evolutionary algorithms is developed for forecasting rainfall process in a tropical environment.

This paper proposes the hybrid models by combining the ANFIS model and different optimization methods (e.g. particle swarm optimization algorithm (PSO), genetic algorithm (GA), and differential evolutionary (DE) algorithm) for forecasting monthly rainfall. The primary objective focuses on the development of hybrid models, namely, ANFIS-PSO, ANFIS-GA, and ANFIS-DE, which have not been investigated previously for rainfall forecasting. The feasibility of the proposed models is validated against the conventional ANFIS model. The modeling performances are evaluated using model efficiency indices and graphical comparisons. The applied hybrid methods can be used for flood management and analysis in the Pahang River, Malaysia. Located in a tropical environment of Malaysia, the river basin has experienced a few serious floods in the past two decades which emphasizes the need for rainfall trend forecasting.

\section{Methodology}

\subsection{Adaptive Neuro-Fuzzy Inference System}

The fuzzy set approach was first introduced by Zaheh [30], based on a combination of neural network (NN) and the concept of fuzzy logic (FL), so that it could possibly catch the advantages of both in a solitary structure. The integration of FL with fuzzy inference systems (FISs) can be used for model development with fewer or ambiguous data. Among all the fuzzy systems, Sugeno's system is the most prevailing approach [31]. In contrast to NN, FL has a higher ability in the learning procedure to adjust its condition. Consequently, the NN can be utilized to naturally change the membership function (MFs) and decrease the error rate in the designation of rules in FL.

The development of the ANFIS model structure is based on two components, (i) the learning process (nodes) in which the use of the membership function (MF) in the conversion of the input attributes to the fuzzy values that vary between 0 and 1 is usually conducted [32] and (ii) the ANFIS model uses fuzzy rules (i.e., IF-THEN conditions) to certify the relationship between the inputs and the target. The MF is the main part that influences the predictability performance of the ANFIS model and, therefore, the appropriate selection of the MF is one of the predefined stages for the modeling [33]. The structure of an ANFIS network includes five different layers: fuzzification, product, normalization, de-fuzzification, and output. These are shown for a network with two input variables $\left(x_{1}\right.$ and $\left.x_{2}\right)$ in Figure 1a.

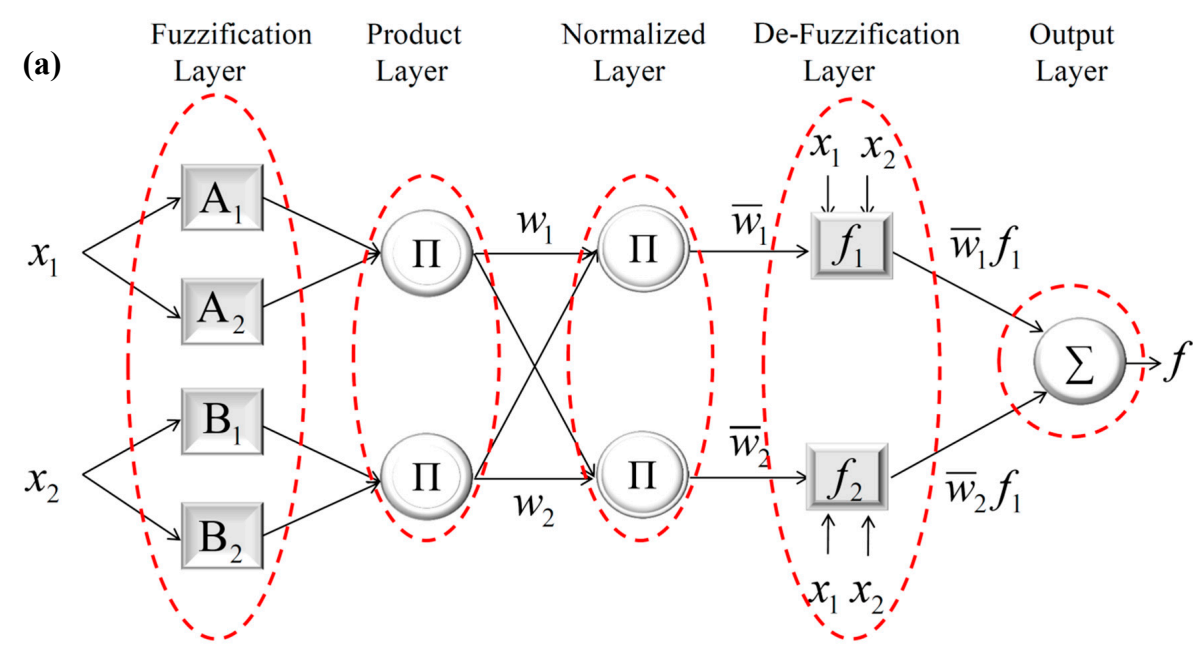

Figure 1. Cont. 
(b)

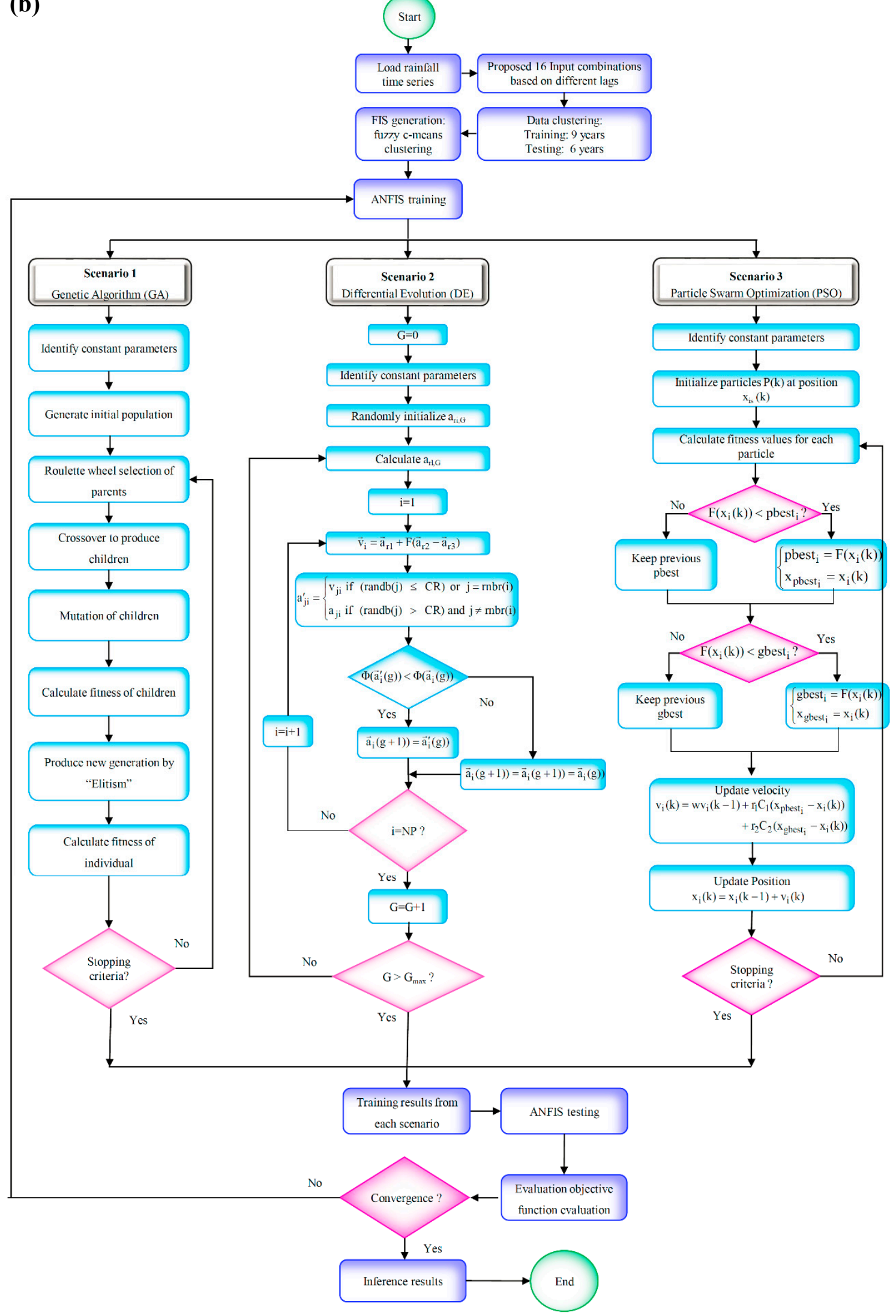

Figure 1. (a) Adaptive neuro-fuzzy inference system model architecture for 2 inputs and 1 output, (b) General flow chart of a hybrid ANFIS model for different scenarios. 
In the first layer, each node adjusts to a function parameter. The output of the "fuzzification" layer is a value of membership degree that is estimated using the inputs of MFs.

$$
\begin{array}{ll}
O_{1, i}=\mu_{A_{i}}(x) & i=1,2 \\
O_{1, i}=\mu_{B_{i-2}}(x) & i=3,4
\end{array}
$$

where $A i$ and $B i$ are fuzzy sets, whereas $\mu_{A_{i}}$ and $\mu_{B_{i-2}}$ are the MF degree for $A i$ and $B i$.

The ordinarily used MFs are triangular-shaped, trapezoidal-shaped, generalized bell-shaped and Gaussian. In the current study, the Gaussian MF is used due to the lower parameters of this MF in relation to the generalized bell-shape MF. The Gaussian-shape MF is defined as follows:

$$
\mu_{A_{i}}(x)=\exp \left[-\left(\frac{x-c_{i}}{2 \sigma_{i}}\right)^{2}\right]
$$

where $\{c i$ and $\sigma i\}$ is the set of MF parameters that can alter the MF shape. The parameters in this layer are referred to as antecedent parameters.

The rules in the ANFIS network are designated due to the premise and consequent parts and are put away in fuzzy rule-based systems. The nonlinear premise and linear consequent parameters are related to layers 1 and 2, respectively. To attain an optimum model, the values of these linear and nonlinear parameters must be adjusted using an optimization algorithm. Due to the classical algorithm's drawbacks, such as being stuck in local minima and slow convergences, three different evolutionary algorithms, namely, PSO, GA, and DE, are employed in this study to optimize the ANFIS model's design.

\subsection{Particle Swarm Optimization (PSO)}

Kennedy and Eberhart [34] introduced the particle swarm optimization, which was modeled after the social characteristics of birds and fish. The main advantages of PSO are the simple procedure, the small amount of calculation, and instant convergences, which have made it suitable for solving different complex and nonlinear engineering problems. Briefly, PSO considers that every particle changes its position in the search space concerning the best position that it has ever been in and the best position near its neighbor. For particles to achieve an optimal or limited circumstance calculation, they usually change their positions within the multi-dimensional search space. PSO determines the initial particle swarm, $P(k)$, in such a way that each particle's $x_{i s}(k)$ position $\left(P_{i} \in P(k)\right)$ in the hyperspace equals $k=0$, which is the first step. This is followed by the second step where each particle's $F$ function performance is evaluated using the position of the particle $\left(x_{i}(k)\right)$ :

$$
\text { if } F\left(x_{i}(k)\right)<\text { pbest }_{i} \quad \text { then }\left\{\begin{array}{l}
\text { pbest }_{i}=F\left(x_{i}(k)\right) \\
x_{\text {pbest }_{i}}=x_{i}(k)
\end{array}\right.
$$

where pbest is the best position of the ith particle.

The optimal performance of individual particles is evaluated in the third step in the following ways:

$$
\text { if } F\left(x_{i}(k)\right)<\text { gbest }_{i} \text { then }\left\{\begin{array}{l}
\text { gbest }_{i}=F\left(x_{i}(k)\right) \\
x_{\text {gbest }_{i}}=x_{i}(k)
\end{array}\right.
$$

where gbest is the global best value attained by the different particles of swarm.

In the fourth step, the velocity vector of each particle is changed using the equation:

$$
v_{i}(k)=w v_{i}(k-1)+r_{1} C_{1}\left(x_{\text {pbest }_{i}}-x_{i}(k)\right)+r_{2} C_{2}\left(x_{\text {gbest }}-x_{i}(k)\right)
$$


where $r_{1}$ and $r_{2}$ represent random parameters which lie within 0 and 1 ; and the parameters (C1 and $C 2=2$ ) [27]. In Equation (6), $w$ represents the inertia weight parameter. A balance between the local and global swarm performance can be achieved by a careful selection of these parameters to reduce the number of iterations. As per [34], the value of $w$ can be determined as follows:

$$
w=w_{\max }-\frac{w_{\max }-w_{\min }}{\text { iter }_{\max }} . \text { iter }
$$

where the initial and final weights are represented as $w_{\min }$ and $w_{\max }$, respectively, while the maximum iteration value and iteration number are represented by $i t r_{\text {max }}$ and $i t r$, respectively. The particles are transformed to their new locations in the fifth stage using the following equation:

$$
x_{i}(k)=x_{i}(k-1)+v_{i}(k)
$$

\subsection{Genetic Algorithm (GA) Optimization}

The conceptual structure of the genetic algorithm (GA) was first introduced by [28], based on Darwin's theory. The GA as a derivative-free stochastic method of optimization is one of the most well-known and oldest evolutionary algorithms and most widely employed EA approach in solving many engineering problems. It can be used to solve nonlinear, stochastic, and non-differentiable problems that may seem impossible by using gradient-based methods [35]. Goldberg and Holland [36] asserted that the population points for each iteration in the GA are randomly generated, and the best population point desires the optimum solution similar to the final outcome. The number of the population size for this algorithm was selected similarly to the process considered in the PSO which is equal to 100. The basic steps of GA include three important components. The first component is the creation of an initial population using the randomly selected $m$ th individual, giving rise to the first population. Entering the $m$ th individual and generating the output is the second component. Each of the outputs is evaluated based on the objective function known as a fitness function. The expected demand from each individual to achieve the desired objective is determined by the evaluation. From the fittest individual in the previous generation, a new generation is created.

In the reproduction process, the selection of chromosomes from the current generation based on the fitness of each chromosome to produce new generation offspring is done using the "selection" operator. The chromosomes with higher probabilities are chosen to modify and be employed in the next generation. Finally, the crossover operator which is a pivotal operator in the genetic algorithm is defined to generate child chromosomes from two different parent chromosomes. Indeed, using this operator, two new chromosomes are generated which have a higher fitness than the two entering chromosomes (parents). The crossover explores and exploits the new and old solutions, respectively, using a trial and error procedure. The crossover rate in this study is considered 0.75 .

\subsection{Differential Evolution (DE) Optimization}

Storn and Price [37] presented the differential evolution (DE), a random population-based algorithm [31]. This method is differentiated from the other methods because it uses differential mutation. When a population problem with n-dimensional space must be solved, the fixed vector numbers are randomly created to understand the different search spaces as well as to reach the minimum objective function through evolution over time. In DE, a mutation function $\left(F: I^{\mu} \rightarrow I^{\mu}\right)$ involves the production of a mutated vector $(\mu)$ using the equation:

$$
\vec{v}_{i}=\vec{a}_{r 1}+F\left(\vec{a}_{r 2}-\vec{a}_{r 3}\right) \quad i=1,2, \ldots, \mu
$$

where $r_{1}, r_{2}, r_{3} \in[1,2, \ldots, \mu]$ are randomly designated. $F \in[0,2]$ is a fixed parameter which affects the vector's differential variation. The capacity of the global search algorithm is usually increased by larger $F$ or population size $(\mu)$ quantities. In DE, the crossover operator (CR: $\left.I^{\mu} \rightarrow I^{\mu}\right)$ modifies the 
vectors $\left(\vec{v}_{i}=\left[\vec{v}_{1}, \vec{v}_{2 i}, \ldots, \vec{v}_{d i}\right]\right)$ with a target function $\left(\vec{a}_{i}=\left[\vec{a}_{1 i}, \vec{a}_{2 i}, \ldots, \vec{a}_{d i}\right]\right)$ to generate a trial combination of vectors using the following formula:

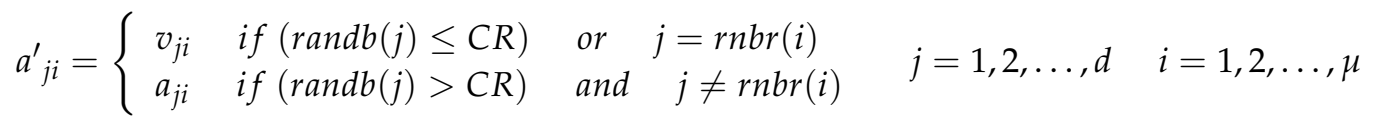

where $\operatorname{randb}(j) \in[0,1]$ equals the randomized generator evaluation by the $j$ th, while rnbr (i) (rnbr (i) $\in$ $1,2, \ldots, d)$ is a random selection index. $C R \in[0,1]$ represents the crossover parameter which increases the individual variations in the population. The population size for DE is considered similar to PSO and GA, equal to 100. The mutation and crossover constants which are obtained using a trial and error process are equal to 0.25 and 0.85 , respectively.

\subsection{Hybridization of ANFIS Model}

This subsection describes the hybridization of the ANFIS model with three evolutionary algorithms (i.e., PSO, GA, and DE). The hybrid ANFIS models, encoded in the MATLAB environment, were used for rainfall time series forecasting. The structure of the proposed hybrid techniques is presented in Figure 1a. For the modeled rainfall time series, the initial hybrid models (ANFIS-PSO, ANFIS-GA, and ANFIS-DE) were developed for the study area using a training dataset. Subsequently, each previously mentioned evolutionary algorithm was adopted to optimize the ANFIS models by looking for the optimum values of premise and consequent parameters. After finding the optimum values of premise and consequent parts, the evolutionary-based hybrid methods of ANFIS regression were inferred and employed in rainfall time series forecasting.

The rainfall time series was split into two subsets: training and testing. All the employed monthly rainfall datasets were collected during the period 2000-2014. In this study, the first nine years of datasets were considered as training datasets and the rest of the data (2009-2014) were employed as testing datasets. Moreover, the number of inputs in the training phase varied from 1 to 6 lag times (antecedent months), which are presented in 16 different input combination structures as follows:

$$
\begin{gathered}
\text { Model 1: } \mathrm{t}-1 \\
\text { Model 2: } \mathrm{t}-1, \mathrm{t}-2 \\
\text { Model 3: } \mathrm{t}-1, \mathrm{t}-3 \\
\text { Model 4: } \mathrm{t}-1, \mathrm{t}-6 \\
\text { Model 5: } \mathrm{t}-1, \mathrm{t}-12 \\
\text { Model 6: } \mathrm{t}-1, \mathrm{t}-2, \mathrm{t}-3 \\
\text { Model 7: } \mathrm{t}-1, \mathrm{t}-2, \mathrm{t}-6 \\
\text { Model 8: } \mathrm{t}-1, \mathrm{t}-2, \mathrm{t}-12 \\
\text { Model 9: } \mathrm{t}-1, \mathrm{t}-3, \mathrm{t}-6 \\
\text { Model 10: } \mathrm{t}-1, \mathrm{t}-3, \mathrm{t}-12 \\
\text { Model 11: } \mathrm{t}-1, \mathrm{t}-2, \mathrm{t}-3, \mathrm{t}-6 \\
\text { Model 12: } \mathrm{t}-1, \mathrm{t}-2, \mathrm{t}-3, \mathrm{t}-12 \\
\text { Model 13: } \mathrm{t}-1, \mathrm{t}-2, \mathrm{t}-6, \mathrm{t}-12 \\
\text { Model 14: } \mathrm{t}-1, \mathrm{t}-2, \mathrm{t}-3, \mathrm{t}-6, \mathrm{t}-12 \\
\text { Model 15: } \mathrm{t}-1, \mathrm{t}-2, \mathrm{t}-3, \mathrm{t}-12, \mathrm{t}-24
\end{gathered}
$$


All forecasting models have only one output (i.e., rainfall as the objective variable). The antecedent's values are obtained using the auto-correlation function statistical approach.

After determining the training dataset and input combinations, the model configuration was presented. Using training datasets, an initial ANFIS-EA (PSO, GA, and DE) was generated. As the premise and consequent parameters related to the initial ANFIS models were not optimized, the value of these parameters was optimized through an optimizing process using EA (PSO, GA, and DE). In this study, the fuzzy c-means (FCM) clustering approach was considered to generate the fuzzy inference system (FIS). Using different clusters, the fuzzy if-then rules were produced, and the optimum values of premise and consequent parameters were obtained during the optimization process performed by the PSO, GA, and DE algorithms. Moreover, it should be noted that the Gaussian membership function (MF), which is smooth and has the lowest parameters in relation to other smooth MFs such as the bell-shape MF, was used. Readers are recommended to look over the literature on the adapted hybrid models for more informative details [38].

\subsection{Modeling Performance Indicators}

Predictive models such as mathematical models (i.e., machine learning models) are usually evaluated using numerical indicators. The hybrid models developed in this study were inspected using four statistical metrics, including root mean square error (RMSE), mean absolute error (MAE), correlation coefficient (CC), and Willmott's index (WI) [39-41]. The mathematical expression can be presented as follows:

$$
\begin{gathered}
\mathrm{RMSE}=\sqrt{\frac{1}{N} \sum_{t=1}^{n}\left(R_{o}-R_{f}\right)^{2}} \\
\mathrm{MAE}=\frac{1}{N} \sum_{t=1}^{n}\left|R_{o}-R_{f}\right| \\
\mathrm{CC}=\frac{\sum_{i=1}^{N}\left(R_{o}-\overline{R_{o}}\right)\left(R_{f}-\overline{R_{f}}\right)}{\sqrt{\sum_{i=1}^{N}\left(R_{o}-\overline{R_{o}}\right)^{2} \sum_{i=1}^{N}\left(R_{f}-\overline{R_{f}}\right)^{2}}} \\
\mathrm{WI}=1-\left[\frac{\sum_{i=1}^{N}\left(R_{o}-R_{f}\right)^{2}}{\sum_{i=1}^{N}\left(\left|R_{f}-\overline{R_{o}}\right|+\left|R_{o}-\overline{R_{o}}\right|\right)^{2}}\right], 0 \leq W I \leq 1 .
\end{gathered}
$$

where $R_{o}$ and $R_{f}$ are the observed and forecasted values of rainfall data, whereas $\overline{R_{o}}$ and $\overline{R_{f}}$ are the mean value of the observed and forecasted values of rainfall data.

\subsection{Uncertainty Analysis}

The Monte Carlo simulation (MCS) was used in this study to estimate the uncertainty bounds of a predictor model. Indeed, MCS was simulated using ANFIS-based methods.

To achieve a range of numbers, where the results of a model can be located on that range, a result-dependent factor called the uncertainty analysis is used. Indeed, the uncertainty analysis represents the probability bounds in the model estimations that envelopes the values of target parameters in its range. Two different indices which are considered in uncertainty analyses are 95 percent predicted uncertainties (95PPU) and the d-factor. The 95PPU indicates that estimated percentage of predicted data that is limited by 95 percent predicted uncertainties and the $\mathrm{d}$-factor assesses the average of the confidence band width. 


\section{Case Study and Hydrological Data Description}

Malaysia is considered a tropical region that experiences several events of monsoon rainfall. Rainfall process is the main trigger for flood events that consequently affect society infrastructure and human lives directly. Hence, establishing a hybrid intelligence predictive model can provide the basic knowledge for protecting the studied watershed. In this research, Pahang watershed metrological information was used to build the predictive model. The Pahang watershed is located in Pahang, the largest state of Peninsular Malaysia. It is limited by Kelantan in the north, Johor in the south, Terengganu and the South China Sea in the east and Selangor and Negeri Sembilan in the west. The total area of the watershed is approximately $36,137 \mathrm{~km}^{2}$ (Figure 2). The climate of the area is dominated by the northeast monsoon rainfall influence. The average annual rainfall ranges between 1609 and $2132 \mathrm{~mm}$ in the basin. In general, the extreme rainfall events occur between November and March. In this study, the monthly rainfall data for the period 2000-2014 were used for the development of hybrid models. The rainfall time series was obtained from the Department of Irrigation and Drainage (DID). It is worth mentioning that the modeling carried out in this research was based on the univariate concept that included only the rainfall information to forecast the rainfall itself. This is highly significant, especially in a watershed that comprises several metrological information sources. The highly stochastic behavior of rainfall patterns often produces floods, and thus the main motivation for this research was to develop an accurate model for rainfall forecasting, which could be used for anticipating the possible occurrence of floods. For this purpose, ANFIS combinations with a couple of evolutionary algorithms were developed.

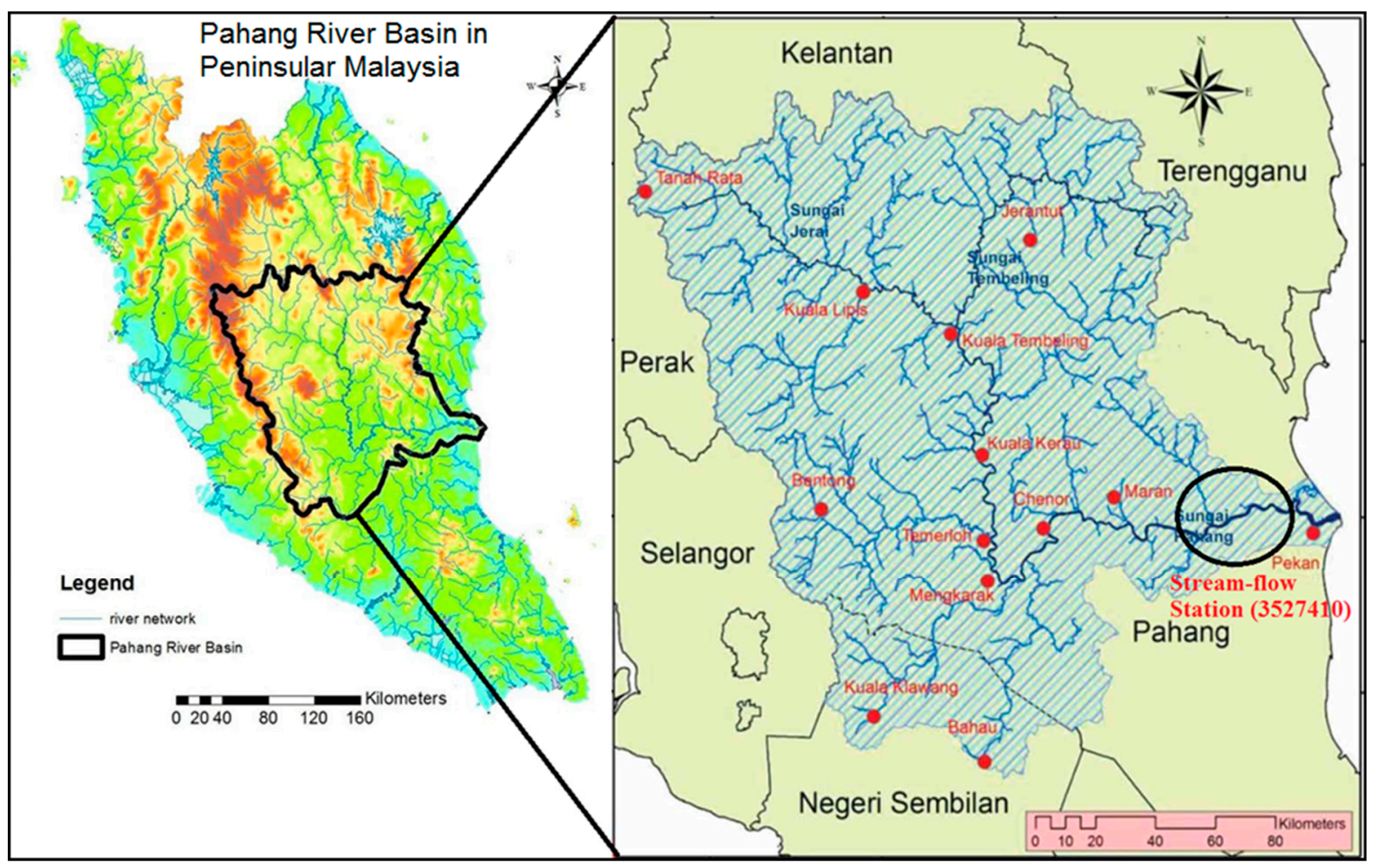

Figure 2. Location of Pahang River basin and the rain gauges in Peninsular Malaysia.

\section{Application and Analysis}

ANFIS learning process implementation was conducted based on the RMSE criterion to determine the optimal number of membership functions of the ANFIS model. The statistical performance of hybrid and classical ANFIS models during training and test phases are tabulated in Table 1a-d. It can be seen from the table that the performance of different models significantly increased when all inputs were incorporated (i.e., model 16), compared to other input combinations. 
Table 1. Statistical performance of the predictive models in forecasting monthly rainfall during the training and testing phases.

\begin{tabular}{|c|c|c|c|c|c|c|c|c|}
\hline \multicolumn{9}{|c|}{ (a) ANFIS-based model } \\
\hline Models & $\begin{array}{c}\text { RMSE } \\
(\mathrm{mm})\end{array}$ & $\begin{array}{l}M A E \\
(m m)\end{array}$ & $C C$ & $W I$ & $\begin{array}{c}\text { RMSEE } \\
(\mathrm{mm})\end{array}$ & $\begin{array}{l}M A E \\
(m m)\end{array}$ & $C C$ & WI \\
\hline & \multicolumn{4}{|c|}{ Training phase } & \multicolumn{4}{|c|}{ Testing phase } \\
\hline Model 1 & 4.23 & 3.16 & 0.492 & 0.564 & 5.32 & 3.69 & 0.439 & 0.478 \\
\hline Model 2 & 4.02 & 2.85 & 0.575 & 0.698 & 4.04 & 2.73 & 0.749 & 0.788 \\
\hline Model 3 & 2.96 & 2.22 & 0.799 & 0.882 & 3.00 & 2.31 & 0.864 & 0.913 \\
\hline Model 4 & 3.41 & 2.43 & 0.723 & 0.810 & 4.69 & 2.91 & 0.627 & 0.714 \\
\hline Model 5 & 2.87 & 1.95 & 0.820 & 0.888 & 4.54 & 2.82 & 0.664 & 0.759 \\
\hline Model 6 & 3.08 & 2.30 & 0.780 & 0.865 & 2.63 & 2.00 & 0.897 & 0.938 \\
\hline Model 7 & 3.40 & 2.26 & 0.724 & 0.806 & 3.17 & 2.28 & 0.848 & 0.911 \\
\hline Model 8 & 3.05 & 2.07 & 0.793 & 0.871 & 3.03 & 2.13 & 0.866 & 0.922 \\
\hline Model 9 & 3.20 & 2.13 & 0.760 & 0.850 & 4.16 & 2.14 & 0.723 & 0.801 \\
\hline Model 10 & 3.06 & 2.20 & 0.796 & 0.880 & 3.72 & 2.42 & 0.807 & 0.850 \\
\hline Model 11 & 2.18 & 1.50 & 0.896 & 0.941 & 2.20 & 1.49 & 0.930 & 0.962 \\
\hline Model 12 & 2.73 & 1.83 & 0.842 & 0.911 & 2.46 & 1.87 & 0.924 & 0.947 \\
\hline Model 13 & 2.78 & 1.94 & 0.832 & 0.903 & 2.51 & 1.66 & 0.915 & 0.946 \\
\hline Model 14 & 1.92 & 1.20 & 0.923 & 0.960 & 1.73 & 1.12 & 0.960 & 0.978 \\
\hline Model 15 & 2.10 & 1.36 & 0.897 & 0.943 & 1.13 & 0.75 & 0.984 & 0.991 \\
\hline Model 16 & 1.40 & 0.91 & 0.956 & 0.976 & 0.99 & 0.65 & 0.987 & 0.994 \\
\hline \multicolumn{9}{|c|}{ (b) ANFIS-PSO } \\
\hline Models & $\begin{array}{c}\text { RMSE } \\
(\mathrm{mm})\end{array}$ & $\begin{array}{l}\text { MAE } \\
(m m)\end{array}$ & $C C$ & $W I$ & $\begin{array}{c}\text { RMSE } \\
(\mathrm{mm})\end{array}$ & $\begin{array}{l}\text { MAE } \\
(m m)\end{array}$ & $C C$ & WI \\
\hline & \multicolumn{4}{|c|}{ Training phase } & \multicolumn{4}{|c|}{ Testing phase } \\
\hline Model 1 & 4.24 & 3.17 & 0.488 & 0.561 & 5.31 & 3.67 & 0.444 & 0.483 \\
\hline Model 2 & 3.63 & 2.66 & 0.671 & 0.782 & 4.31 & 2.92 & 0.692 & 0.756 \\
\hline Model 3 & 2.66 & 1.93 & 0.841 & 0.908 & 2.63 & 2.02 & 0.895 & 0.939 \\
\hline Model 4 & 3.25 & 2.31 & 0.751 & 0.840 & 4.46 & 2.69 & 0.671 & 0.755 \\
\hline Model 5 & 2.76 & 1.95 & 0.835 & 0.898 & 4.40 & 2.74 & 0.689 & 0.786 \\
\hline Model 6 & 2.84 & 1.96 & 0.816 & 0.888 & 2.21 & 1.53 & 0.927 & 0.960 \\
\hline Model 7 & 3.32 & 2.33 & 0.740 & 0.835 & 2.67 & 1.92 & 0.898 & 0.937 \\
\hline Model 8 & 2.68 & 1.75 & 0.846 & 0.907 & 2.75 & 1.81 & 0.892 & 0.939 \\
\hline Model 9 & 3.11 & 2.13 & 0.775 & 0.861 & 4.02 & 2.05 & 0.745 & 0.819 \\
\hline Model 10 & 2.53 & 1.67 & 0.864 & 0.924 & 3.07 & 2.18 & 0.871 & 0.912 \\
\hline Model 11 & 2.04 & 1.33 & 0.910 & 0.950 & 1.81 & 1.20 & 0.953 & 0.975 \\
\hline Model 12 & 1.77 & 1.20 & 0.936 & 0.965 & 1.58 & 1.11 & 0.967 & 0.981 \\
\hline Model 13 & 2.30 & 1.53 & 0.891 & 0.940 & 2.24 & 1.36 & 0.931 & 0.961 \\
\hline Model 14 & 1.16 & 0.75 & 0.973 & 0.985 & 1.14 & 0.62 & 0.982 & 0.991 \\
\hline Model 15 & 1.44 & 0.83 & 0.953 & 0.975 & 0.73 & 0.44 & 0.993 & 0.996 \\
\hline Model 16 & 0.86 & 0.51 & 0.984 & 0.991 & 0.47 & 0.28 & 0.997 & 0.998 \\
\hline \multicolumn{9}{|c|}{ (c) ANFIS-GA } \\
\hline Models & $\begin{array}{c}\text { RMSE } \\
(\mathrm{mm})\end{array}$ & $\begin{array}{l}\text { MAE } \\
(\mathrm{mm})\end{array}$ & $C C$ & $W I$ & $\begin{array}{c}\text { RMSE } \\
(\mathrm{mm})\end{array}$ & $\begin{array}{l}\text { MAE } \\
(\mathrm{mm})\end{array}$ & $C C$ & WI \\
\hline & \multicolumn{4}{|c|}{ Training phase } & \multicolumn{4}{|c|}{ Testing phase } \\
\hline Model 1 & 4.24 & 3.17 & 0.488 & 0.561 & 5.31 & 3.67 & 0.442 & 0.481 \\
\hline Model 2 & 3.59 & 2.62 & 0.679 & 0.791 & 4.28 & 2.85 & 0.697 & 0.758 \\
\hline Model 3 & 2.91 & 2.10 & 0.805 & 0.881 & 2.84 & 2.28 & 0.876 & 0.928 \\
\hline Model 4 & 3.43 & 2.37 & 0.720 & 0.822 & 4.12 & 2.47 & 0.738 & 0.794 \\
\hline Model 5 & 2.60 & 1.78 & 0.856 & 0.911 & 3.55 & 2.28 & 0.812 & 0.890 \\
\hline Model 6 & 2.77 & 2.02 & 0.826 & 0.895 & 2.40 & 1.72 & 0.915 & 0.951 \\
\hline Model 7 & 3.42 & 2.15 & 0.718 & 0.812 & 2.98 & 2.02 & 0.868 & 0.922 \\
\hline Model 8 & 2.90 & 2.01 & 0.816 & 0.884 & 3.36 & 2.28 & 0.833 & 0.900 \\
\hline Model 9 & 3.11 & 2.07 & 0.774 & 0.860 & 4.12 & 2.12 & 0.728 & 0.806 \\
\hline Model 10 & 2.50 & 1.63 & 0.872 & 0.930 & 3.26 & 2.27 & 0.851 & 0.898 \\
\hline Model 11 & 2.37 & 1.60 & 0.876 & 0.930 & 2.40 & 1.53 & 0.917 & 0.954 \\
\hline Model 12 & 2.33 & 1.59 & 0.885 & 0.935 & 1.83 & 1.35 & 0.954 & 0.975 \\
\hline Model 13 & 2.40 & 1.57 & 0.880 & 0.932 & 2.06 & 1.30 & 0.942 & 0.967 \\
\hline Model 14 & 1.50 & 0.93 & 0.956 & 0.976 & 1.38 & 0.78 & 0.974 & 0.986 \\
\hline Model 15 & 1.55 & 0.92 & 0.945 & 0.970 & 0.92 & 0.56 & 0.989 & 0.994 \\
\hline Model 16 & 1.21 & 0.69 & 0.967 & 0.982 & 0.83 & 0.51 & 0.991 & 0.995 \\
\hline \multicolumn{9}{|c|}{ (d) ANFIS-DE } \\
\hline \multirow[t]{2}{*}{ Models } & $\begin{array}{c}\text { RMSE } \\
(\mathrm{mm})\end{array}$ & $\begin{array}{l}M A E \\
(m m)\end{array}$ & $C C$ & $W I$ & $\begin{array}{c}\text { RMSE } \\
(\mathrm{mm})\end{array}$ & $\begin{array}{l}M A E \\
(m m)\end{array}$ & $C C$ & WI \\
\hline & \multicolumn{4}{|c|}{ Training phase } & & Testi & ohase & \\
\hline Model 1 & 4.17 & 3.20 & 0.513 & 0.600 & 5.29 & 3.60 & 0.449 & 0.486 \\
\hline Model 2 & 3.66 & 2.61 & 0.666 & 0.781 & 4.07 & 2.61 & 0.736 & 0.791 \\
\hline Model 3 & 2.71 & 2.00 & 0.834 & 0.900 & 2.75 & 2.17 & 0.885 & 0.935 \\
\hline Model 4 & 3.42 & 2.41 & 0.720 & 0.819 & 4.05 & 2.61 & 0.741 & 0.813 \\
\hline Model 5 & 2.62 & 1.86 & 0.853 & 0.913 & 2.73 & 2.03 & 0.894 & 0.940 \\
\hline
\end{tabular}


Table 1. Cont

\begin{tabular}{|c|c|c|c|c|c|c|c|c|}
\hline \multicolumn{9}{|c|}{ (d) ANFIS-DE } \\
\hline Models & $\begin{array}{c}\text { RMSE } \\
(\mathrm{mm})\end{array}$ & $\begin{array}{l}M A E \\
(m m)\end{array}$ & $C C$ & $W I$ & $\begin{array}{c}\text { RMSE } \\
(\mathrm{mm})\end{array}$ & $\begin{array}{l}M A E \\
(\mathrm{~mm})\end{array}$ & $C C$ & $W I$ \\
\hline & \multicolumn{4}{|c|}{ Training phase } & \multicolumn{4}{|c|}{ Testing phase } \\
\hline Model 6 & 2.74 & 1.89 & 0.830 & 0.895 & 2.35 & 1.66 & 0.917 & 0.955 \\
\hline Model 7 & 3.32 & 2.09 & 0.740 & 0.824 & 3.04 & 2.07 & 0.862 & 0.919 \\
\hline Model 8 & 2.85 & 1.91 & 0.824 & 0.889 & 2.88 & 1.96 & 0.881 & 0.934 \\
\hline Model 9 & 3.17 & 2.18 & 0.763 & 0.850 & 4.20 & 2.16 & 0.715 & 0.797 \\
\hline Model 10 & 2.51 & 1.70 & 0.867 & 0.930 & 3.12 & 2.23 & 0.865 & 0.908 \\
\hline Model 11 & 2.22 & 1.42 & 0.893 & 0.940 & 2.12 & 1.40 & 0.936 & 0.965 \\
\hline Model 12 & 2.43 & 1.68 & 0.875 & 0.930 & 2.09 & 1.65 & 0.941 & 0.966 \\
\hline Model 13 & 2.50 & 1.68 & 0.866 & 0.923 & 2.32 & 1.51 & 0.925 & 0.956 \\
\hline Model 14 & 1.36 & 0.92 & 0.963 & 0.980 & 1.37 & 0.76 & 0.974 & 0.987 \\
\hline Model 15 & 1.58 & 0.99 & 0.943 & 0.970 & 0.70 & 0.46 & 0.994 & 0.997 \\
\hline Model 16 & 1.14 & 0.67 & 0.971 & 0.985 & 0.73 & 0.38 & 0.993 & 0.996 \\
\hline
\end{tabular}

* Bold numbers present the best input combination accuracy results.

The RMSE values were found to vary in the range of $0.99-5.32,0.47-5.31,0.83-5.31$, and 0.70-5.29 mm for ANFIS-based, ANFIS-PSO, ANFIS-GA, and ANFIS-DE models, respectively. In quantitative analysis, the hybrid ANFIS-PSO model enhanced the performance of the absolute error measures (RMSE and MAE) over the ANFIS-based model by $38-43 \%$ during training and $52-56 \%$ during testing phases. The ANFIS-GA model showed an enhancement over the ANFIS-based model by $14-24 \%$ during the training phase and $16-21 \%$ during the testing phase, whereas ANFIS-DE displayed an enhancement over the ANFIS-based model by $18-26 \%$ during the training phase and $26-41 \%$ over the testing phase. It can be observed that the major increase in the quantitative measures was presented for the ANFIS-PSO. It important to indicate that the root mean square error is the essential numerical indictor to determine the performance of machine learning modeling for time series forecasting [42-45]. The minimum values of RMSE obtained for the ANFIS-PSO, ANFIS-GA, and ANFIS-DE were $0.47,0.83$, and $0.70 \mathrm{~mm}$, respectively. The results attained for all hybrid ANFIS models showed an acceptable error level that could be managed by water resource and climatology decision makers using the threshold-based design [46].

The proficiency of the different models was also examined using some graphical presentations, such as observed rainfall values versus forecasted values in scatterplot graphs and Taylor diagrams. The time variation and scatterplots of observed versus simulated hybrid models are provided in Figure 3. It is obvious form the figures that the values given by the ANFIS-PSO, ANFIS-GA, and ANFIS-DE are closer to the observed values than those of the ANFIS-based model for most of the input combinations. Based on the presented scatterplots of observed and forecasted rainfall and assuming the trend line as $y=a x+b$ ( $a$ and $b$ are the coefficients of fit line), it can be seen that for the hybrid ANFIS-PSO, ANFIS-GA, and ANFIS-DE, the $a$ and $b$ coefficients are closer to 1 and 0 with a higher determination of coefficient values.
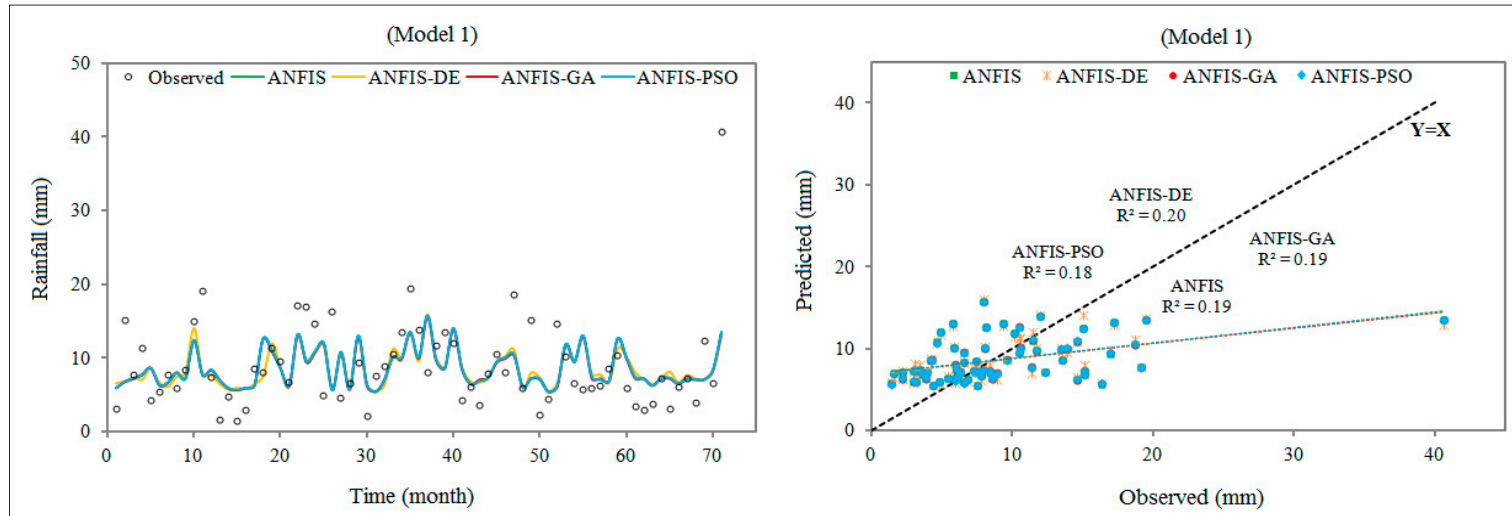

Figure 3. Cont. 

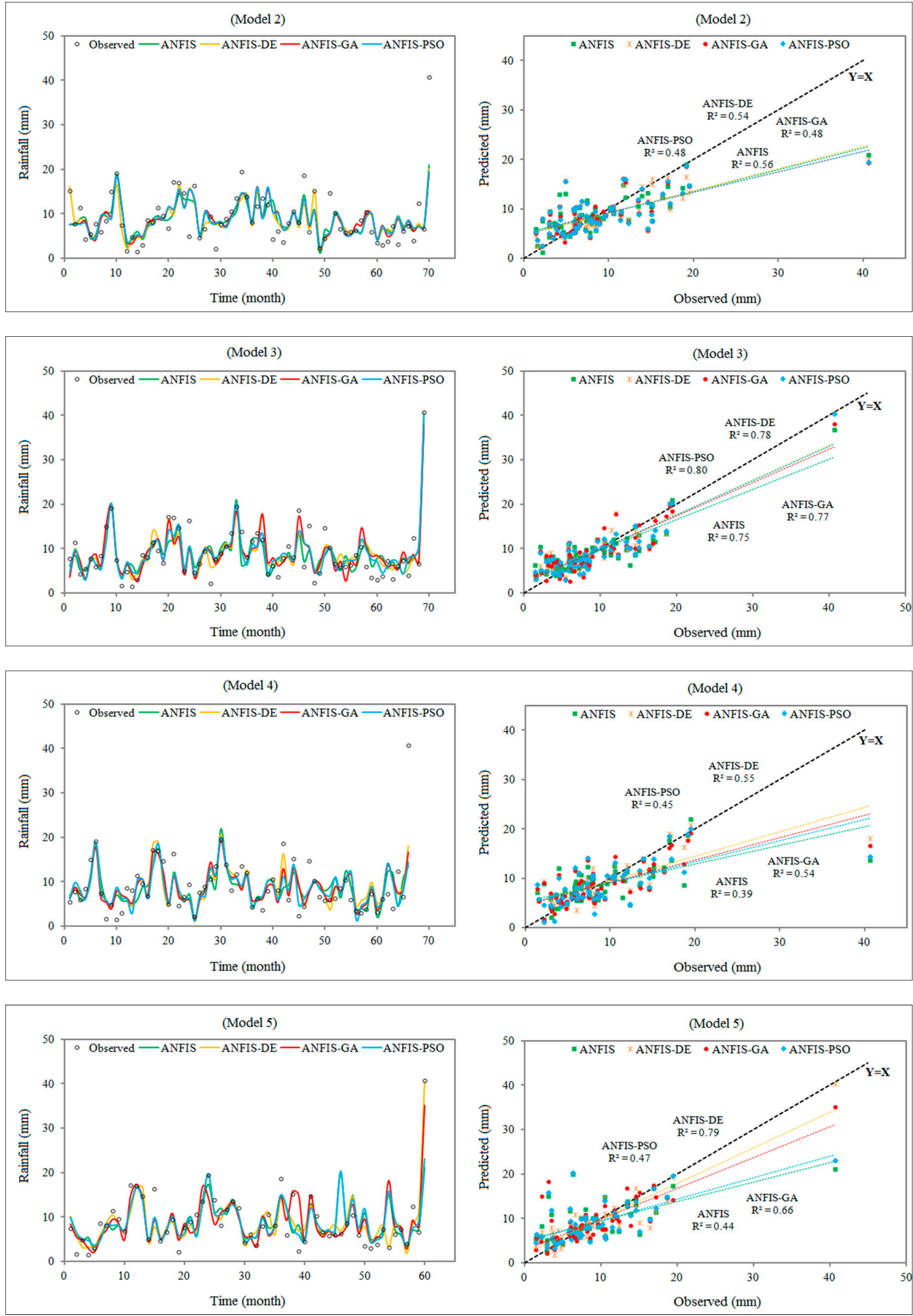

Figure 3. Cont. 

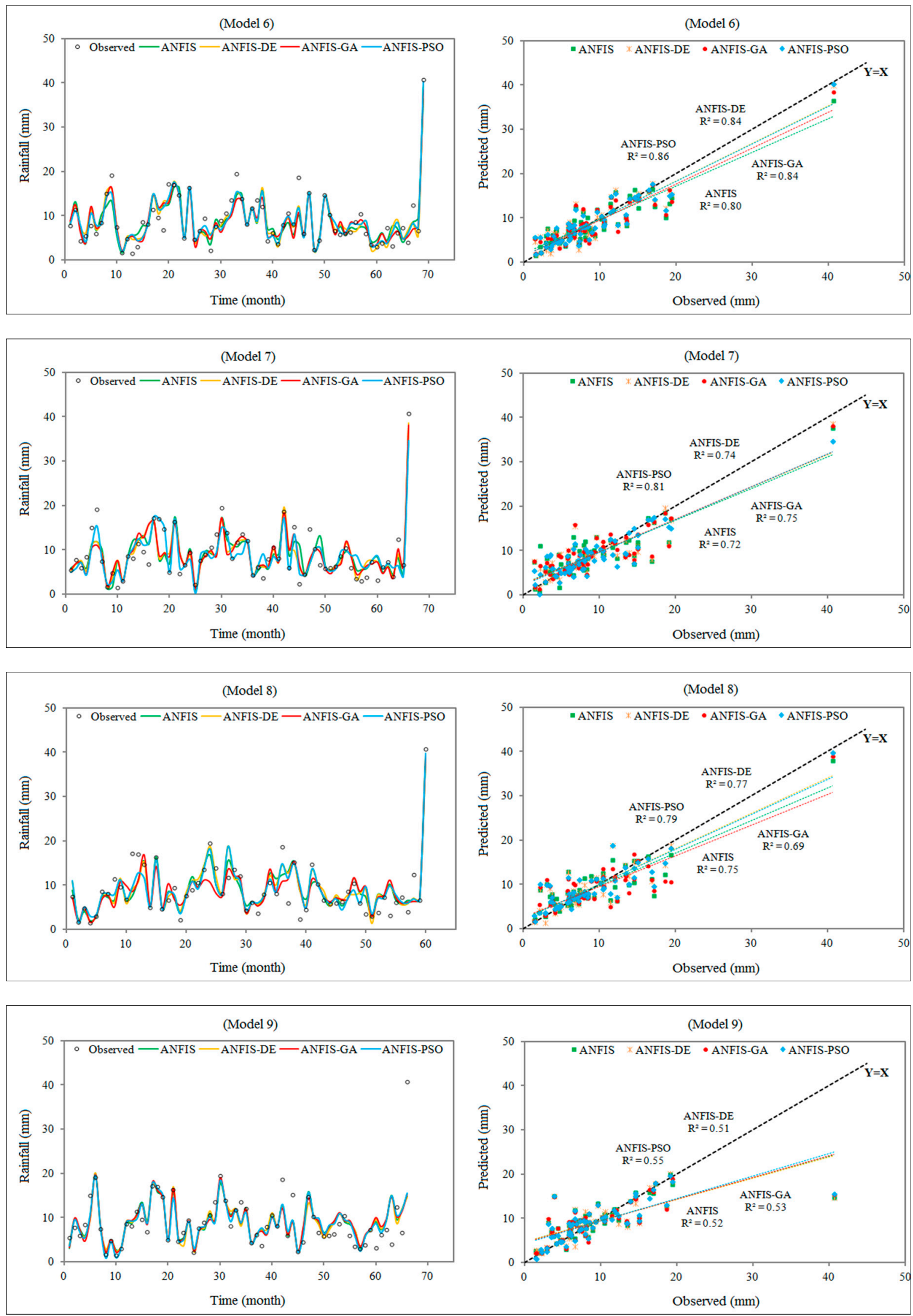

Figure 3. Cont. 

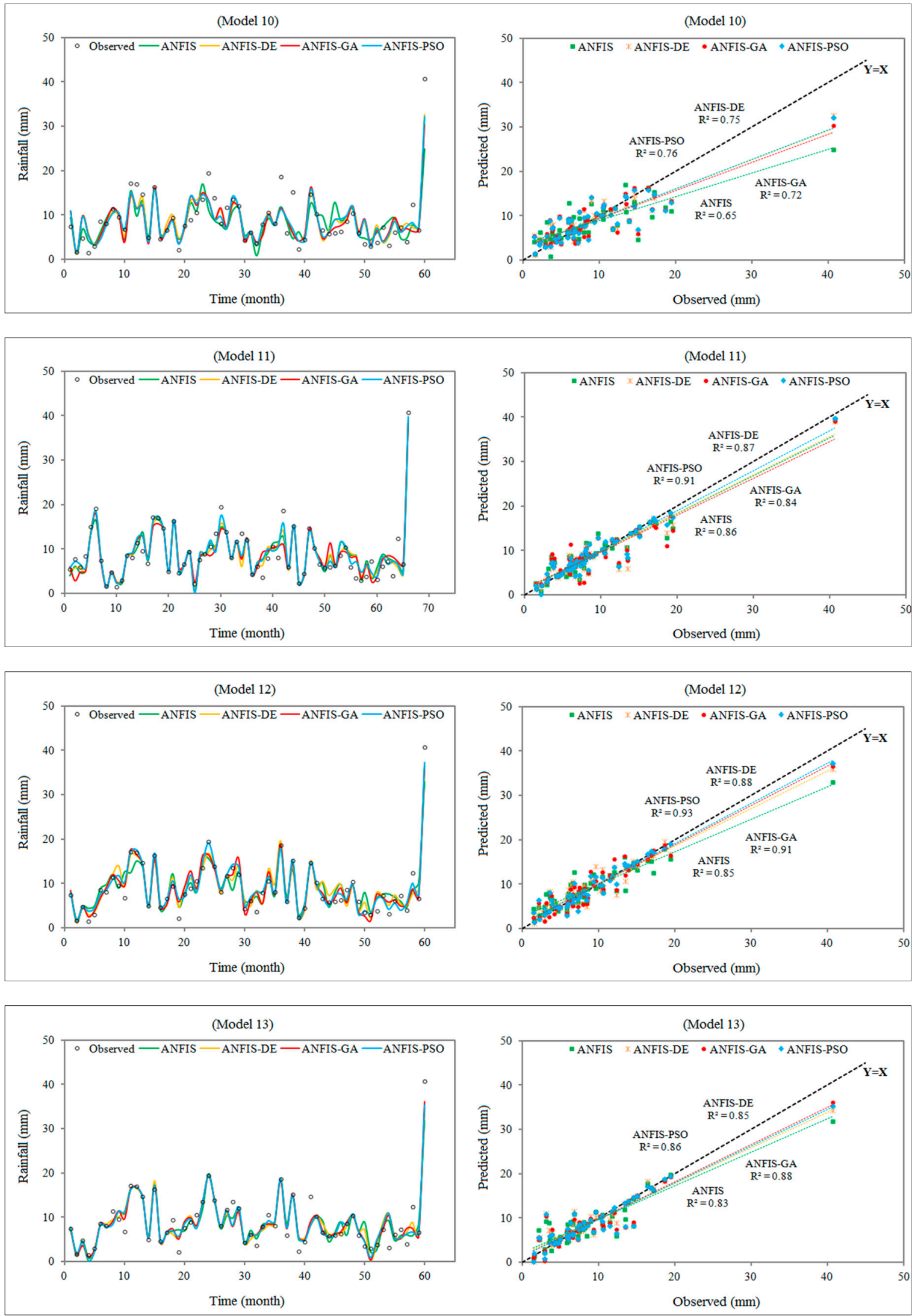

Figure 3. Cont. 

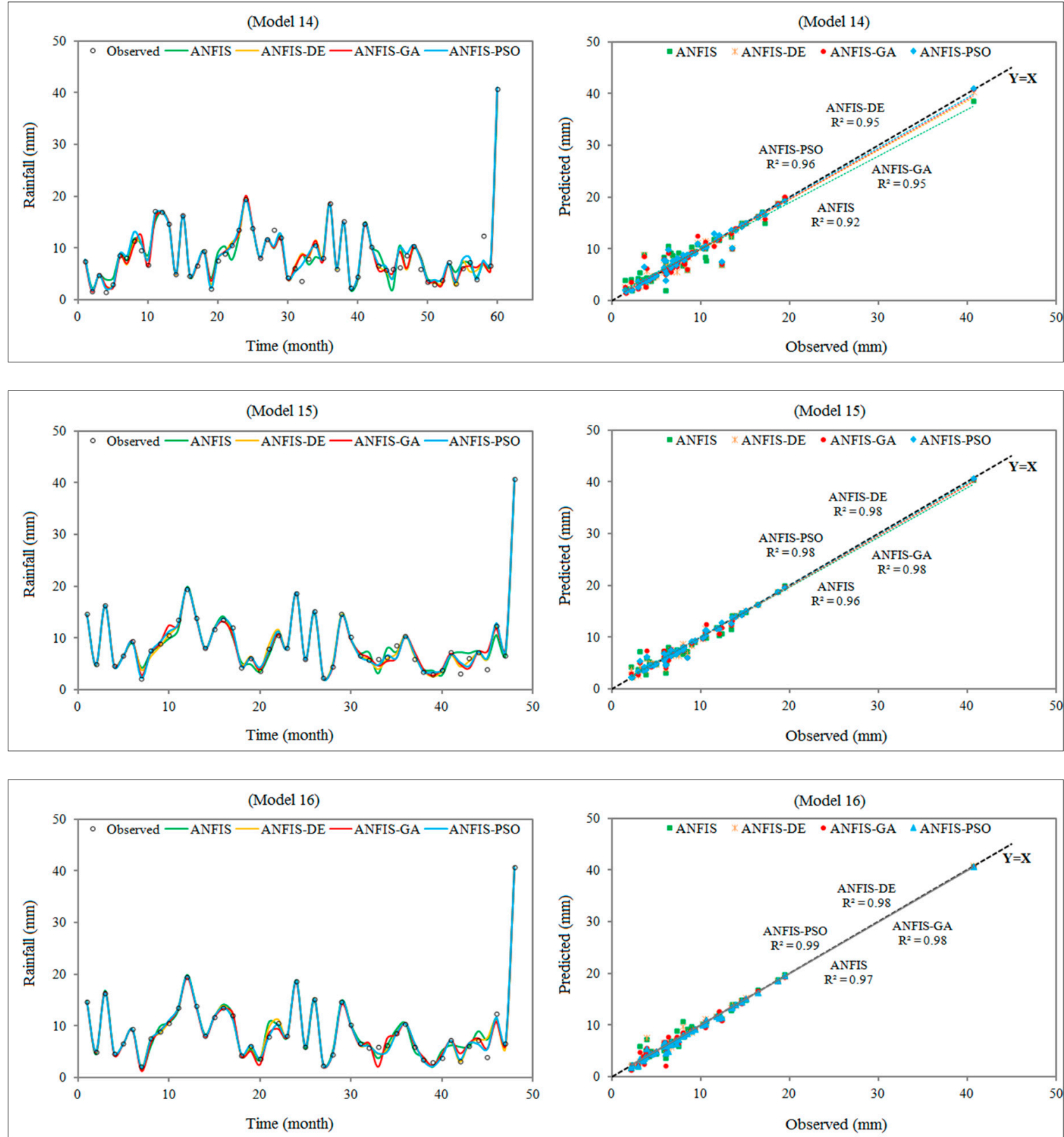

Figure 3. Time series and scatterplot of observed and forecasted rainfall by three hybrid models, namely, ANFIS-particle swarm optimization (PSO), ANFIS-genetic algorithm (GA), and ANFIS-differential evolution (DE), and the classical ANFIS model for different input combinations over the testing phase of the models.

Figure 4 shows a graphical presentation using Taylor diagrams [47]. A Taylor diagram is a method for graphically condensing how intently a model (or several models) matches observations. The similarity between the predictive models and the observation records is quantified in terms of their correlation coefficient and standard deviations. The figures outline the proposed hybrid models and the comparable ANFIS-based model in terms of the mentioned indictors to denote the degree of the prediction skills. The distance from the reference point (observed) is a measure of the centered RMSE [47]. Accordingly, a perfect model (being in full concurrence with the observations) is set apart by the reference point with the correlation coefficient equivalent to 1 , and a similar abundancy of varieties contrasted with the observations [48]. The visualization of results revealed that the ANFIS-PSO model 
results were closer to the observation points than the ANFIS-GA, ANFIS-DE, and ANFIS-based model results, reaffirming the better accuracy of the hybrid ANFIS-PSO.
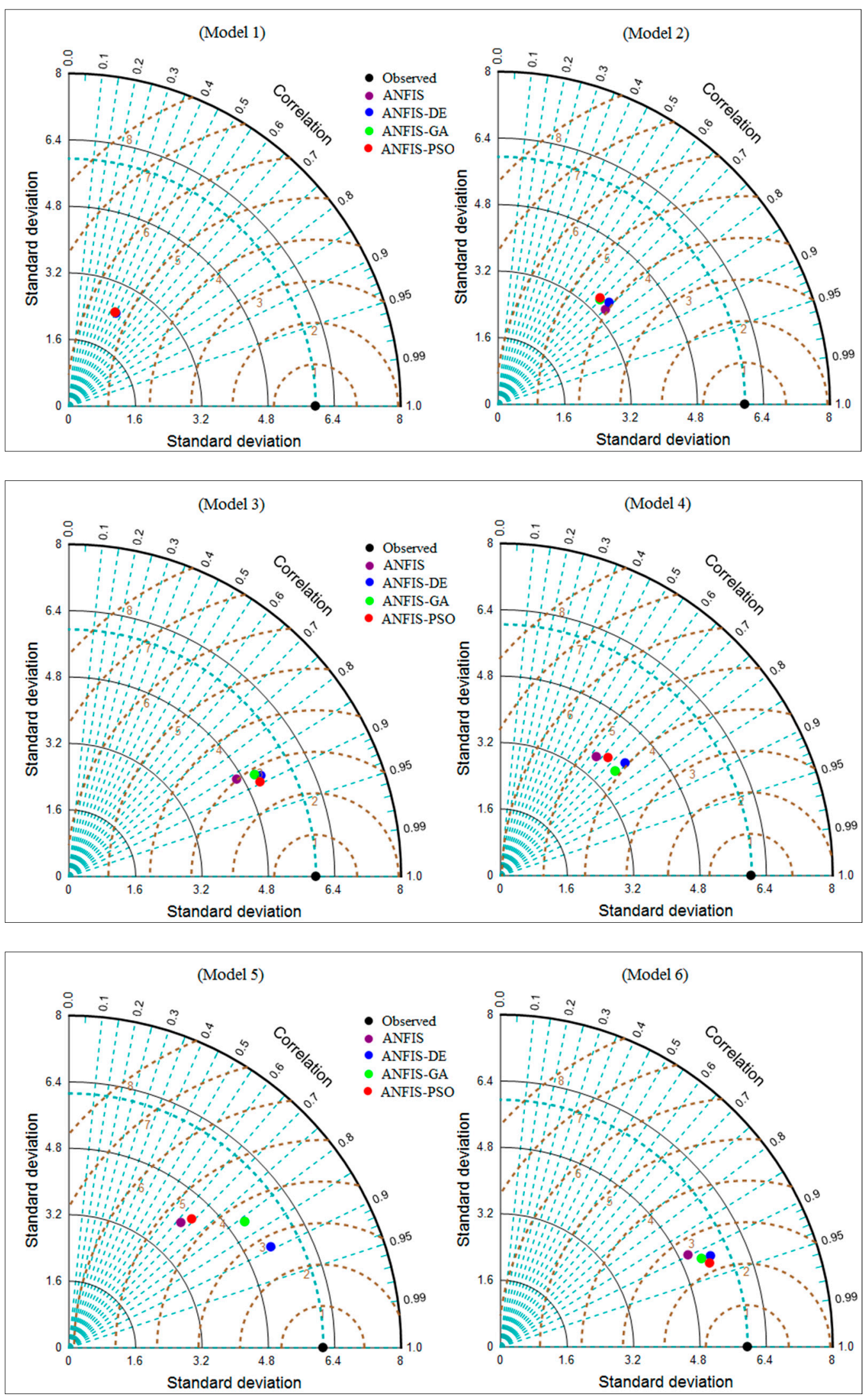

Figure 4. Cont. 

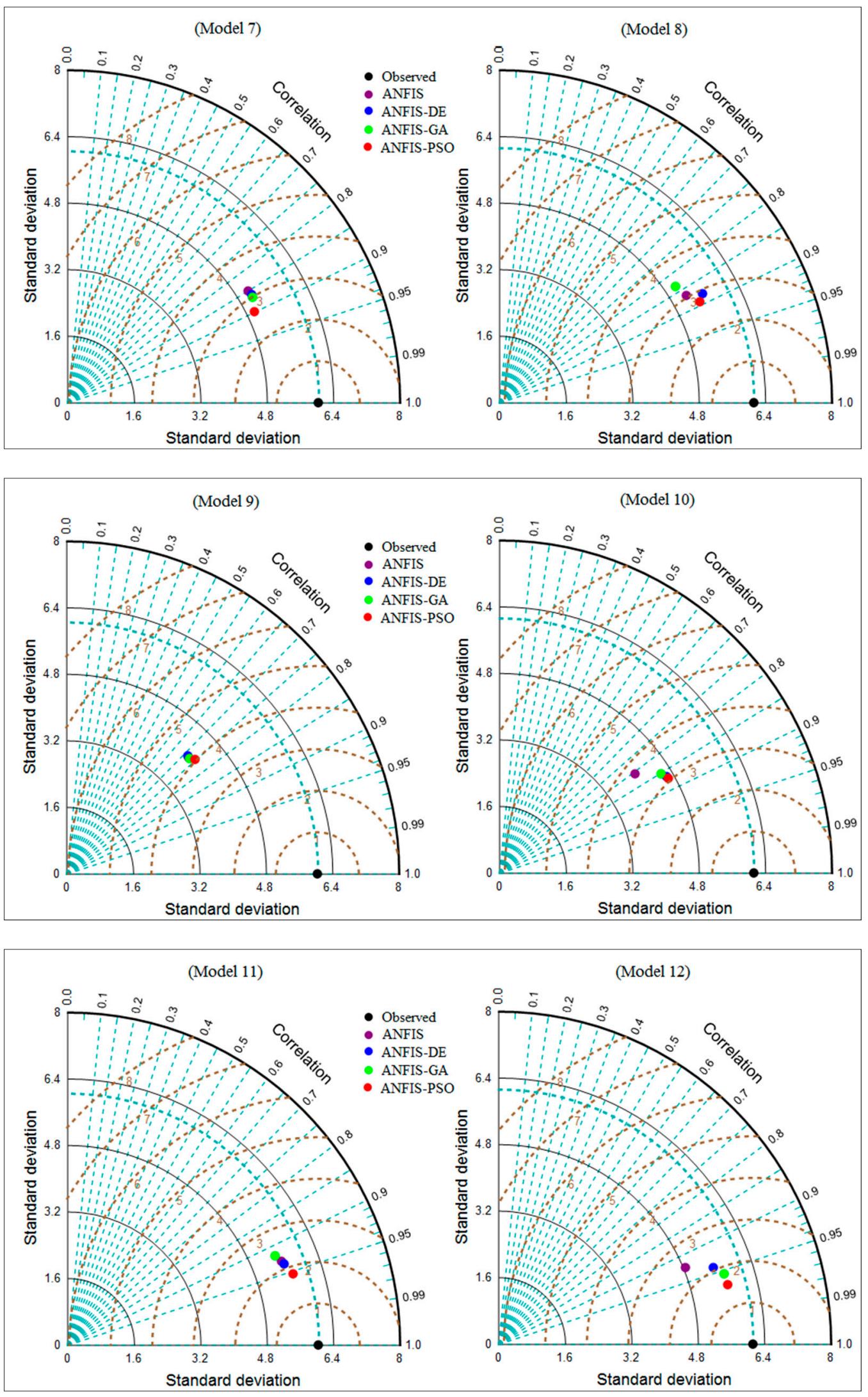

Figure 4. Cont. 

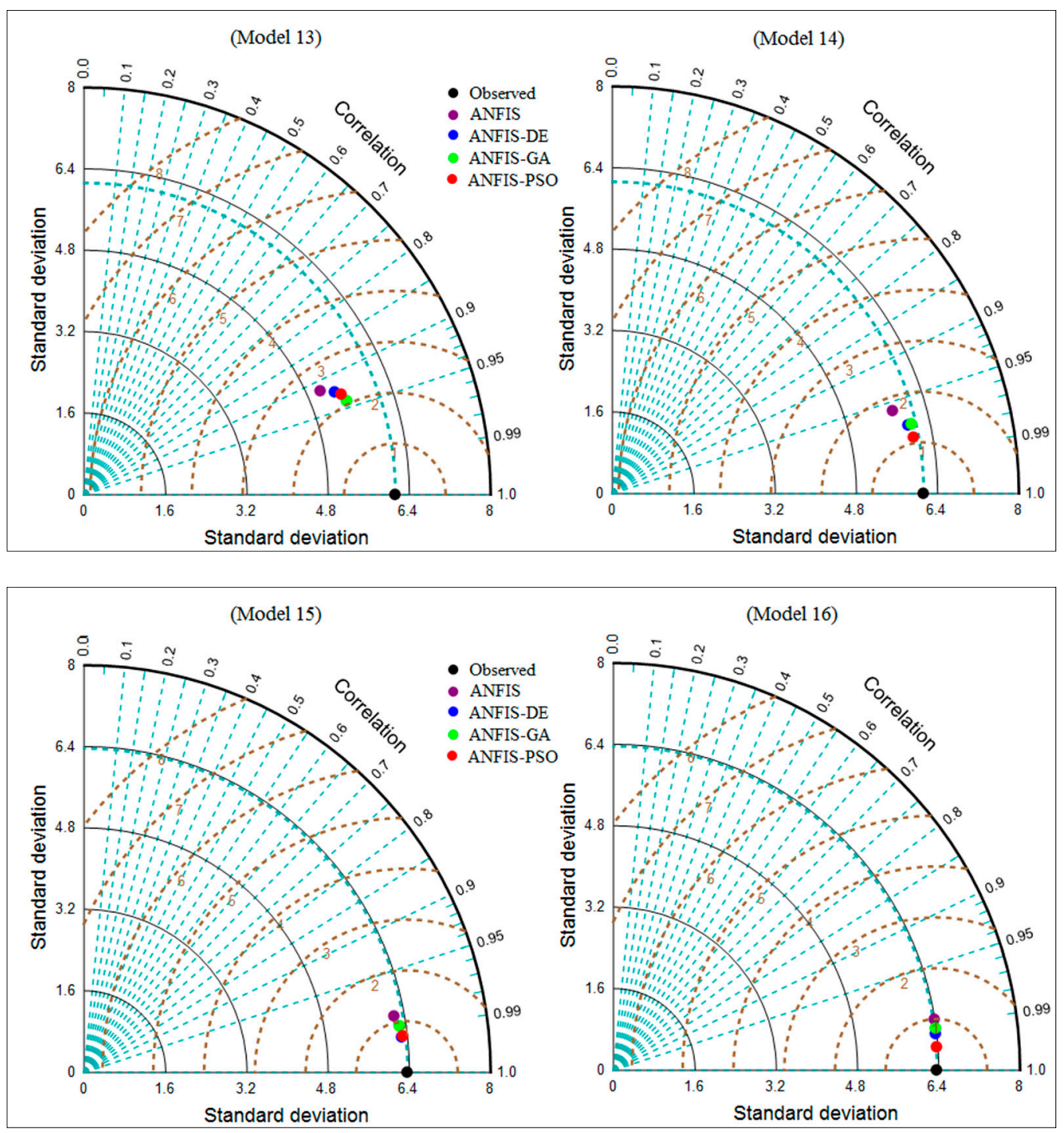

Figure 4. Taylor diagrams for the graphical presentation of the performance of three hybrid models, namely, ANFIS-PSO, ANFIS-GA, and ANFIS-DE, and the classical ANFIS model for different input combinations during the testing phase of the models.

As previously discussed, one of the main aims of this study was to examine the uncertainty analysis of the different ANFIS-based methods using d-factor and 95PPU criteria. The reduction in average values of lower and upper bounds (lower than the standard deviation (SD) of observed data) and the increase in observed data in 95PPU in uncertainty result in a more desirable uncertainty for each model. The uncertainty indices of $d$-factor and 95PPU for testing samples are presented in Table 2 for 64 models (four ANFIS-based models and 16 different input combinations, Equations (11)-(26)). In addition, the 95PPU values bracketed for Model 16 of each proposed model are given in Figure 5. As seen in Table 2 and Figure 5, minimum values bracketed by 95PPU are approximately $11 \%-12 \%$ and maximum values bracketed by this index are approximately $91.67 \%, 91.03 \%, 89.74 \%$, and $88.46 \%$ for ANFIS-PSO, ANFIS-GA, ANFIS-DE, and ANFIS, respectively. Moreover, the maximum and minimum values of the d-factor for ANFIS-PSO, ANFIS-GA, ANFIS-DE, and ANFIS are 0.14-1.43, 0.14-1.43, $0.14-1.44$, and $0.15-1.44$, respectively. 
Table 2. Uncertainty indices of different ANFIS-based models during model testing.

\begin{tabular}{|c|c|c|c|c|c|}
\hline Indicators & Models & ANFIS-PSO & ANFIS-GA & ANFIS-DE & ANFIS \\
\hline \multirow{16}{*}{$d$-factor } & Model 1 & 0.14 & 0.14 & 0.14 & 0.15 \\
\hline & Model 2 & 0.68 & 0.69 & 0.69 & 0.72 \\
\hline & Model 3 & 0.68 & 0.67 & 0.67 & 0.65 \\
\hline & Model 4 & 0.69 & 0.69 & 0.68 & 0.67 \\
\hline & Model 5 & 0.67 & 0.65 & 0.65 & 0.61 \\
\hline & Model 6 & 1.17 & 1.18 & 1.18 & 1.19 \\
\hline & Model 7 & 0.95 & 0.96 & 0.96 & 0.98 \\
\hline & Model 8 & 1.02 & 1.02 & 1.02 & 1.03 \\
\hline & Model 9 & 0.99 & 0.99 & 0.99 & 0.98 \\
\hline & Model 10 & 0.88 & 0.88 & 0.88 & 0.88 \\
\hline & Model 11 & 1.28 & 1.28 & 1.29 & 1.30 \\
\hline & Model 12 & 1.30 & 1.31 & 1.31 & 1.32 \\
\hline & Model 13 & 1.29 & 1.29 & 1.30 & 1.31 \\
\hline & Model 14 & 1.43 & 1.43 & 1.44 & 1.44 \\
\hline & Model 15 & 1.38 & 1.39 & 1.40 & 1.42 \\
\hline & Model 16 & 1.41 & 1.41 & 1.42 & 1.43 \\
\hline \multirow{16}{*}{ 95PPU } & Model 1 & 12.29 & 12.29 & 12.29 & 12.29 \\
\hline & Model 2 & 60.67 & 60.67 & 60.11 & 60.67 \\
\hline & Model 3 & 57.63 & 56.50 & 55.37 & 50.28 \\
\hline & Model 4 & 58.62 & 58.05 & 57.47 & 55.75 \\
\hline & Model 5 & 65.48 & 64.88 & 64.29 & 61.31 \\
\hline & Model 6 & 76.84 & 76.84 & 76.84 & 75.71 \\
\hline & Model 7 & 66.67 & 67.24 & 64.94 & 65.52 \\
\hline & Model 8 & 76.19 & 75.60 & 74.40 & 72.62 \\
\hline & Model 9 & 70.11 & 69.54 & 68.39 & 65.52 \\
\hline & Model 10 & 73.81 & 73.21 & 72.02 & 70.83 \\
\hline & Model 11 & 79.31 & 78.74 & 78.16 & 77.59 \\
\hline & Model 12 & 85.71 & 85.71 & 85.12 & 85.12 \\
\hline & Model 13 & 82.74 & 82.14 & 81.55 & 81.55 \\
\hline & Model 14 & 85.12 & 84.52 & 84.52 & 83.33 \\
\hline & Model 15 & 89.10 & 89.10 & 88.46 & 85.26 \\
\hline & Model 16 & 91.67 & 91.03 & 89.74 & 88.46 \\
\hline
\end{tabular}

* Bold numbers present the best input combination accuracy results.
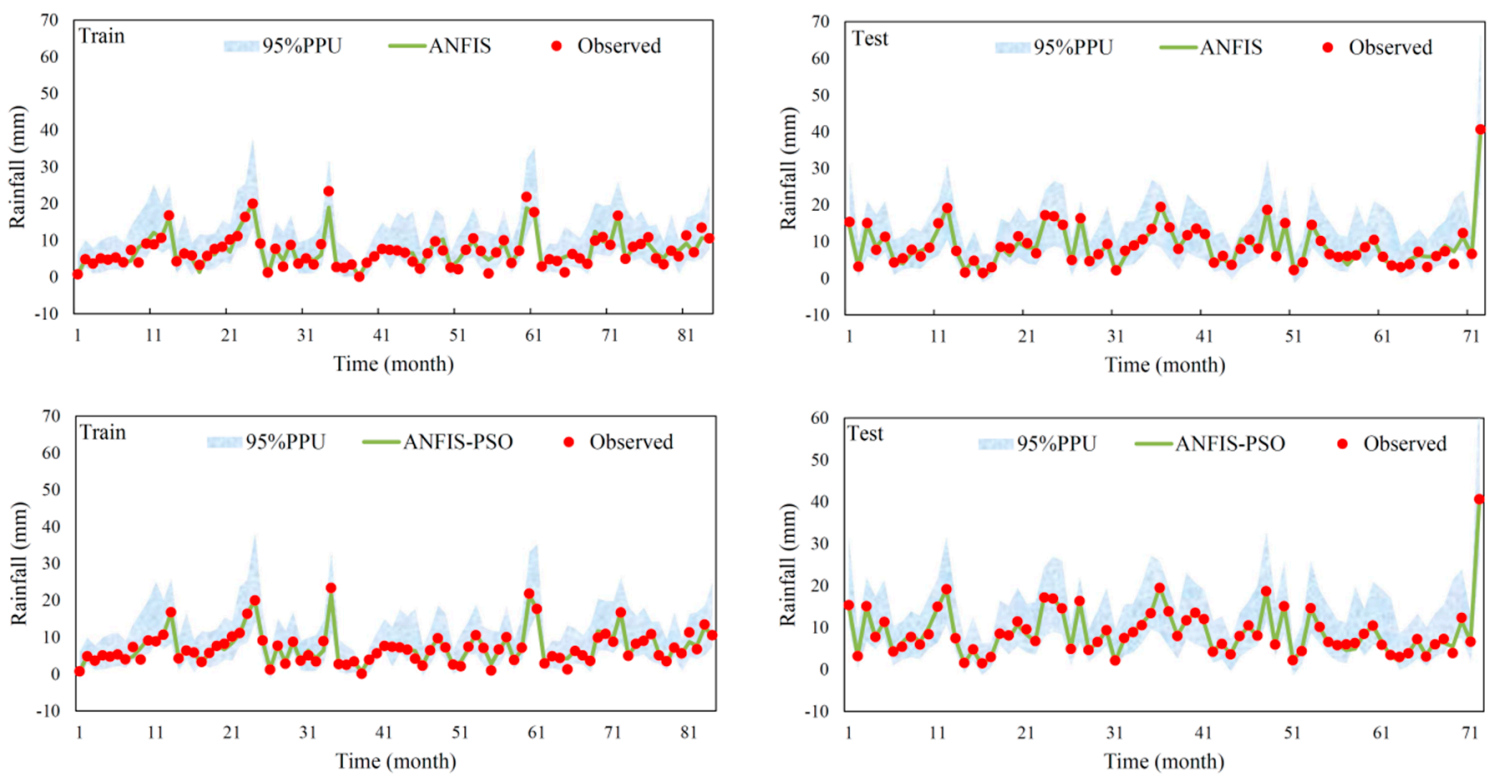

Figure 5. Cont. 

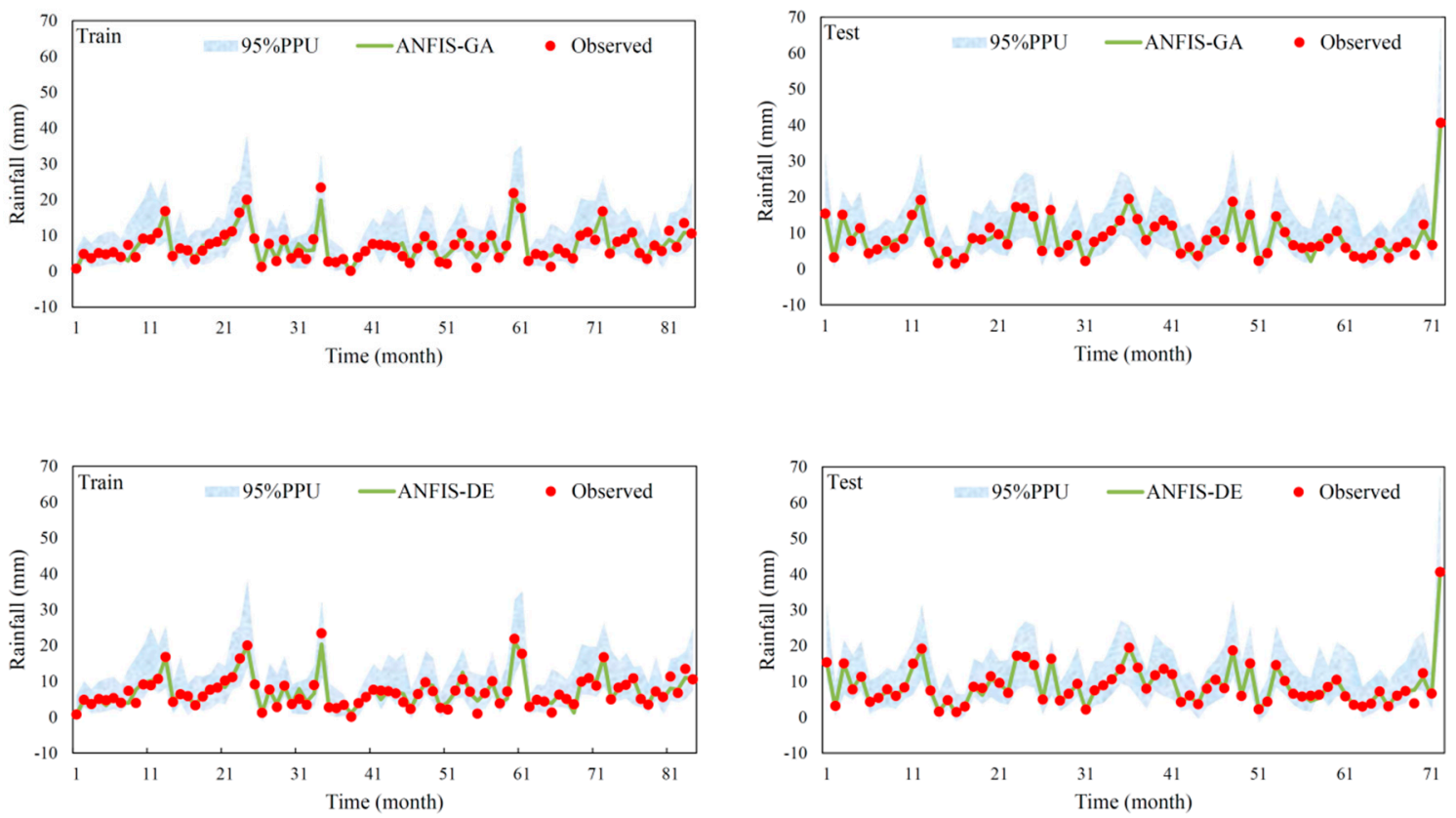

Figure 5. Comparative plots of observed and forecasted rainfall patterns obtained using ANFIS-based, ANFIS-PSO, ANFIS-GA, and ANFIS-DE models.

In accordance with the established research [49], the computed value for 95PPU should be considered at least $80 \%$ of predicted values, whereas, for some areas, the use of $50 \%$ of data in the 95PPU bound is acceptable. Due to the values attained for all ANFIS-based models for the d-factor and 95PPU, it can be derived that all observed and predicted values are within the 95PPU band for all models except model 1 which used lag 1 as the input variable in rainfall forecasting so that $50 \%$ of the observed data fell within this bound. By considering the minimum value of 95PPU as $80 \%$ of predicted values, models 12 to 16 for all ANFIS-based models are within this 95PPU level. Therefore, for all models except model 1 and especially for model 12s to 16, the "passing" degree of uncertainty is achieved in rainfall forecasting. Simulation results for hybrid ANFIS models are better than individual ones because the percentages of values bracketed by 95PPU for hybrid evolutionary ANFIS are higher than those of the ANFIS. In addition, the best and worst uncertainty values are found for ANFIS-PSO and the ANFIS which have the lowest and highest (respectively) values for different input combinations.

Generally, there are three kinds of uncertainty in the simulation of a real-world problemuncertainty appearing from data, from local knowledge, and from a simulator model-so that the level of each uncertainty differs considerably with the type of problem. In this study, the uncertainty arising from data, from local knowledge and from the ANFIS-based models is coming from machine and human errors and unknown problems.

It is worth highlighting that the performance of models used for forecasting rainfall time series should be evaluated according to their ability to forecast rainfall on a multiple temporal scale, such as monthly, seasonally, annually, or inter-annually [50]. However, considering that the stochastic forecasting models developed in this study were used to forecast monthly rainfall one month ahead, only the capability of the models in forecasting monthly rainfall is assessed in this study. Hence, an extension of the current study could be devoted to the investigation of multiple temporal scales.

On the other hand, a general circulation model (GCM) tool could be used to simulate global change with respect to greenhouse emissions that cause rainfall changes on a continental scale based on global warming. Simulating climate on a smaller scale (i.e., a river basin area) is complex due to limitations in the horizontal resolution and parameterization of GCMs [51]. Some techniques were developed for downscaling the GCM scenarios, such as nesting regional climate models (RCMs) within a GCM and 
statistical methods. RCMs can explicitly handle the physical processes that control the regional climate. Such physical processes have been applied indirectly using the linkage between large scale parameters and regional scale climate in statistical models. Statistical techniques are computationally inexpensive and can be easily used for any GCM output and adapted to a regional area compared to dynamic models [52]. Dynamic models based on nesting a fine-scale climate model within a coarse-scale model can produce spatially complete fields of climatological variables (i.e., rainfall) and maintain the spatial correlation and physical relationship between variables. However, due to the intensive computation of dynamic methods, their applications are limited and long-period simulations using various global climate models and multiple greenhouse gas emission scenarios are infeasible [53].

\section{Conclusions}

The current research investigated particle swarm optimization (PSO), genetic algorithm (GA), and differential evolution (DE)-based ANFIS models for forecasting monthly rainfall time series. Different efficient bio-inspired paradigms, namely, PSO, GA, and DE, were compared to identify which method was more appropriate to train the ANFIS model. A good generalization from the ANFIS basically depends on the ANFIS training procedure. The use of an evolutionary-based ANFIS to forecast monthly rainfall was tested for a tropical environment. Rainfall forecasting using an ANFIS trained by PSO, GA, and DE was compared with the classical ANFIS model. In this study, the developed hybrid models were used for forecasting monthly rainfall values using antecedent rainfall values. The obtained results indicated that ANFIS-PSO, ANFIS-GA, and ANFIS-DE were appropriate models for forecasting monthly rainfall. However, it was found that ANFIS-PSO was superior to ANFIS-GA, ANFIS-DE, and the pure ANFIS models. Moreover, the dependability of the ANFIS-based model forecasting was computed using uncertainty analysis. Due to the calculated values of two indices, 95PPU and d-factor, it was concluded that the hybrid evolutionary ANFIS model had an allowable degree of uncertainty in rainfall simulations. Furthermore, after comparing all ANFIS-based models, the hybrid ANFIS (especially ANFIS-PSO) indicated a lower degree of uncertainty in comparison with the classical ANFIS.

Author Contributions: Conceptualization, Z.M.Y.; Formal analysis, Z.M.Y. and H.S.; Funding acquisition, N.A.-A.; Methodology, I.E.; Project administration, Z.M.Y.; Resources, W.H.M.W.M.; Software, I.E.; Supervision, H.B. and S.S.; Validation, Z.M.Y. and S.K.; Visualization, Z.M.Y., Sungwon Kim, and H.A.; Writing—original draft, Z.M.Y. and M.I.G.; Writing-review and editing, Z.M.Y.

Funding: The authors greatly acknowledge the support offered by the Professional Development Research University (PDRU), Grant No. Q.J130000.21A2.04E47.

Acknowledgments: The authors would like to express their gratitude to the Department of Irrigation and Drainage (DID), Malaysia, for providing streamflow data for the Pahang River.

Conflicts of Interest: The authors declare no conflict of interest.

\section{References}

1. Vaze, J.; Post, D.A.; Chiew, F.H.S.; Perraud, J.M.; Viney, N.R.; Teng, J. Climate non-stationarity—Validity of calibrated rainfall-runoff models for use in climate change studies. J. Hydrol. 2010, 394, 447-457. [CrossRef]

2. Khan, N.; Shahid, S.; Juneng, L.; Ahmed, K.; Ismail, T.; Nawaz, N. Prediction of heat waves in Pakistan using quantile regression forests. Atmos. Res. 2019. [CrossRef]

3. Tripathi, S.; Govindaraju, R.S. Statistical forecasting of Indian Summer Monsoon Rainfall: An enduring challenge. Stud. Fuzziness Soft Comput. 2008, 207-224. [CrossRef]

4. Wang, Q.J.; Schepen, A.; Robertson, D.E. Merging seasonal rainfall forecasts from multiple statistical models through Bayesian model averaging. J. Clim. 2012, 25, 5524-5537. [CrossRef]

5. Yuan, F.; Berndtsson, R.; Uvo, C.B.; Zhang, L.; Jiang, P. Summer precipitation prediction in the source region of the Yellow River using climate indices. Hydrol. Res. 2016, 47, 847-856. [CrossRef] 
6. Sittichok, K.; Djibo, A.G.; Seidou, O.; Saley, H.M.; Karambiri, H.; Paturel, J. Statistical seasonal rainfall and streamflow forecasting for the Sirba watershed, West Africa, using sea-surface temperatures. Hydrol. Sci. J. 2016, 61, 805-815. [CrossRef]

7. Štěpnička, M.; Cortez, P.; Donate, J.P.; Štěpničková, L. Forecasting seasonal time series with computational intelligence: On recent methods and the potential of their combinations. Expert Syst. Appl. 2013, 40, 1981-1992. [CrossRef]

8. Pereira, P.J.; Cortez, P.; Mendes, R. Multi-objective Learning of Neural Network Time Series Prediction Intervals. In Progress in Artificial Intelligence; Springer: Cham, Switzerland, 2017; pp. 561-572.

9. Deb, K. Multi-Objective Optimization Using Evolutionary Algorithms; John Wiley \& Sons, LTD: West Sussex, England, 2001; p. 497.

10. Liu, S.; Tai, H.; Ding, Q.; Li, D.; Xu, L.; Wei, Y. A hybrid approach of support vector regression with genetic algorithm optimization for aquaculture water quality prediction. Math. Comput. Model. 2013, 58. [CrossRef]

11. Yaseen, Z.M.; Ghareb, M.I.; Ebtehaj, I.; Bonakdari, H.; Ravinesh, D.; Siddique, R.; Heddam, S.; Yusif, A. Rainfall Pattern Forecasting Using Novel Hybrid Intelligent Model Based ANFIS-FFA. Water Resour. Manag. 2017, 32, 105-122. [CrossRef]

12. Nayak, P.C.; Sudheer, K.P.; Jain, S.K. Rainfall-runoff modeling through hybrid intelligent system. Water Resour. Res. 2007, 43, 1-17. [CrossRef]

13. Pulido-Calvo, I.; Gutiérrez-Estrada, J.C. Improved irrigation water demand forecasting using a soft-computing hybrid model. Biosyst. Eng. 2009, 102, 202-218. [CrossRef]

14. Nourani, V.; Kisi, Ö.; Komasi, M. Two hybrid Artificial Intelligence approaches for modeling rainfall-runoff process. J. Hydrol. 2011, 402, 41-59. [CrossRef]

15. Abdullah, S.S.; Abdul Malek, M.; Mustapha, A.; Aryanfar, A. Hybrid of Artificial Neural Network-Genetic Algorithm for Prediction of Reference Evapotranspiration (ET0) in Arid and Semiarid Regions. J. Agric. Sci. 2014, 6, 191-200. [CrossRef]

16. Abrahart, R.J.; See, L.; Kneale, P.E. Using pruning algorithms and genetic algorithms to optimise network architectures and forecasting inputs in a neural network rainfall-runoff model. J. Hydroinf. 1999, 103-114. [CrossRef]

17. Chau, K.W. Particle swarm optimization training algorithm for ANNs in stage prediction of Shing Mun River. J. Hydrol. 2006, 329, 363-367. [CrossRef]

18. Chau, K.W. A split-step particle swarm optimization algorithm in river stage forecasting. J. Hydrol. 2007, 346, 131-135. [CrossRef]

19. Chen, Y.H.; Chang, F.J. Evolutionary artificial neural networks for hydrological systems forecasting. J. Hydrol. 2009, 367, 125-137. [CrossRef]

20. Kisi, O.; Ozkan, C.; Akay, B. Modeling discharge-sediment relationship using neural networks with artificial bee colony algorithm. J. Hydrol. 2012, 428-429, 94-103. [CrossRef]

21. Asadnia, M.; Chua, L.H.C.; Qin, X.S.; Talei, A. Improved Particle Swarm Optimization-Based Artificial Neural Network for Rainfall-Runoff Modeling. J. Hydrol. Eng. 2014, 19, 1320-1329. [CrossRef]

22. Sudheer, C.; Maheswaran, R.; Panigrahi, B.K.; Mathur, S. A hybrid SVM-PSO model for forecasting monthly streamflow. Neural Comput. Appl. 2013, 1-9. [CrossRef]

23. Taormina, R.; Chau, K. Neural network river forecasting with multi-objective fully informed particle swarm optimization. J. Hydroinf. 2015, 17, 99-112. [CrossRef]

24. Kalteh, A.M. Wavelet Genetic Algorithm-Support Vector Regression (Wavelet GA-SVR) for Monthly Flow Forecasting. Water Resour. Manag. 2015, 29, 1283-1293. [CrossRef]

25. Annaty, M.; Eghbalzadeh, A.; Hosseini, S. Hybrid ANFIS Model for Predicting Scour Depth using Particle Swarm Optimization. Indian J. Sci. Technol. 2015, 8, 326-332. [CrossRef]

26. Yaseen, Z.M.; Ramal, M.M.; Diop, L.; Jaafar, O.; Demir, V.; Kisi, O. Hybrid Adaptive Neuro-Fuzzy Models for Water Quality Index Estimation. Water Resour. Manag. 2018, 32, 2227-2245. [CrossRef]

27. Ghorbani, M.A.; Deo, R.C.; Yaseen, Z.M.; Kashani, M.H. Pan evaporation prediction using a hybrid multilayer perceptron-firefly algorithm ( MLP-FFA ) model: Case study in North Iran. Theor. Appl. Climatol. 2018, 133, 1119-1131. [CrossRef]

28. Ghorbani, M.A.; Deo, R.C.; Karimi, V.; Yaseen, Z.M.; Terzi, O. Implementation of a hybrid MLP-FFA model for water level prediction of Lake Egirdir, Turkey. Stoch. Environ. Res. Risk Assess. 2018, 32, 1683-1697. [CrossRef] 
29. Yaseen, Z.M.; Karami, H.; Ehteram, M.; Mohd, N.S.; Mousavi, S.F.; Hin, L.S.; Kisi, O.; Farzin, S.; Kim, S.; El-shafie, A. Optimization of Reservoir Operation Using New Hybrid Algorithm. KSCE J. Civ. Eng. 2018, 22, 4668-4680. [CrossRef]

30. Zadeh, L. Fuzzy Sets. Inf. Control 1965, 8, 338-353. [CrossRef]

31. Takagi, T.; Sugeno, M. Fuzzy Identification of Systems and Its Applications to Modeling and Control. IEEE Trans. Syst. Man Cybern. 1985, SMC-15, 116-132. [CrossRef]

32. Çekmiş, A.; Hacihasanoğlu, I.; Ostwald, M.J. A computational model for accommodating spatial uncertainty: Predicting inhabitation patterns in open-planned spaces. Build. Environ. 2014, 73, 115-126. [CrossRef]

33. Moosavi, V.; Vafakhah, M.; Shirmohammadi, B.; Behnia, N. A Wavelet-ANFIS Hybrid Model for Groundwater Level Forecasting for Different Prediction Periods. Water Resour. Manag. 2013, 27, 1301-1321. [CrossRef]

34. Kennedy, J.; Eberhart, R. Particle swarm optimization. In Proceedings of the IEEE International Conference on Neural Networks, Perth, Australia, 27 November-1 December 1995; Volume 4, pp. 1942-1948. [CrossRef]

35. Mirjalili, S. Genetic Algorithm. In Evolutionary Algorithms and Neural Networks; Springer: Berlin, Germany, 2019; pp. 43-55.

36. Goldberg, D.E.; Holland, J.H. Genetic algorithms and machine learning. Mach. Learn. 1988, 3, 95-99. [CrossRef]

37. Storn, R.; Price, K. Differential Evolution-A Simple and Efficient Heuristic for Global Optimization over Continuous Spaces. J. Glob. Optim. 1997, 11, 341-359. [CrossRef]

38. Halabi, L.M.; Mekhilef, S.; Hossain, M. Performance evaluation of hybrid adaptive neuro-fuzzy inference system models for predicting monthly global solar radiation. Appl. Energy 2018, 213, 247-261. [CrossRef]

39. Chai, T.; Draxler, R.R. Root mean square error (RMSE) or mean absolute error (MAE)?-Arguments against avoiding RMSE in the literature. Geosci. Model Dev. 2014, 7, 1247-1250. [CrossRef]

40. Willmott, C.J.; Matsuura, K. Advantages of the mean absolute error (MAE) over the root mean square error (RMSE) in assessing average model performance. Clim. Res. 2005, 30, 79-82. [CrossRef]

41. Willmott, C.J. On the validation of models. Phys. Geogr. 1981, 2, 184-194. [CrossRef]

42. Armstrong, J.S.; Collopy, F. Error measures for generalizing about forecasting methods: Empirical comparisons. Int. J. Forecast. 1992, 8, 69-80. [CrossRef]

43. Pandhiani, S.M. Time Series Forecasting by Using Hybrid Models for Monthly Streamflow Data. Appl. Math. Sci. 2015, 9, 2809-2829. [CrossRef]

44. Yaseen, Z.M.; El-Shafie, A.; Afan, H.A.; Hameed, M.; Mohtar, W.H.M.W.; Hussain, A. RBFNN versus FFNN for daily river flow forecasting at Johor River, Malaysia. Neural Comput. Appl. 2016, 27, 1533-1542. [CrossRef]

45. Afan, H.A.; Keshtegar, B.; Mohtar, W.H.M.W.; El-Shafie, A. Harmonize input selection for sediment transport prediction. J. Hydrol. 2017, 552, 366-375. [CrossRef]

46. Kumar, K.K.; Soman, M.K.; Kumar, K.R. Seasonal forecasting of Indian summer monsoon rainfall: A review. Weather 1995, 50, 449-467. [CrossRef]

47. Taylor, K.E. Summarizing multiple aspects of model performance in a single diagram. J. Geophys. Res. Atmos. 2001, 106, 7183-7192. [CrossRef]

48. Heo, K.-Y.; Ha, K.-J.; Yun, K.-S.; Lee, S.-S.; Kim, H.-J.; Wang, B. Methods for uncertainty assessment of climate models and model predictions over East Asia. Int. J. Climatol. 2014, 34, 377-390. [CrossRef]

49. Abbaspour, K.C.; Yang, J.; Maximov, I.; Siber, R.; Bogner, K.; Mieleitner, J.; Zobrist, J. Modelling hydrology and water quality in the pre-alpine/alpine Thur watershed using SWAT. J. Hydrol. 2007, 333, 413-430. [CrossRef]

50. Jiang, P.; Gautam, M.R.; Zhu, J.; Yu, Z. How well do the GCMs/RCMs capture the multi-scale temporal variability of precipitation in the Southwestern United States? J. Hydrol. 2013, 479, 75-85. [CrossRef]

51. Sato, T.; Kimura, F.; Kitoh, A. Projection of global warming onto regional precipitation over Mongolia using a regional climate model. J. Hydrol. 2007, 333, 144-154. [CrossRef]

52. Hellström, C.; Chen, D.; Achberger, C.; Räisänen, J. Comparison of climate change scenarios for Sweden based on statistical and dynamical downscaling of monthly precipitation. Clim. Res. 2001, 19, 45-55. [CrossRef]

53. Maurer, E.P.; Hidalgo, H.G. Utility of daily vs. monthly large-scale climate data: An intercomparison of two statistical downscaling methods. Hydrol. Earth Syst. Sci. 2008, 12, 551-563. [CrossRef]

(C) 2019 by the authors. Licensee MDPI, Basel, Switzerland. This article is an open access article distributed under the terms and conditions of the Creative Commons Attribution (CC BY) license (http:/ / creativecommons.org/licenses/by/4.0/). 